\title{
Highlights
}

- Novel mist cooling system for Li-ion battery module has been developed.

- CFD models have been developed to simulate the performance of mist cooling system.

- Enhanced conventional dry air cooling performance.

- Optimized inlet mist loading faction has been identified.

- Mist cooling system is able to keep the battery variation temperature $<3{ }^{\circ} \mathrm{C}$. 


\section{Novel thermal management system using mist cooling for Lithium-ion battery packs}

Lip Huat Saw ${ }^{\mathrm{a}^{*}}$, Hiew Mun Poon ${ }^{\mathrm{a}}$, Hui San Thiamª ${ }^{\mathrm{a}}$ Zuansi Caib ${ }^{\mathrm{b}}$, Wen Tong Chong ${ }^{\mathrm{c}}$, Nugroho Agung Pambudi ${ }^{d}$, Yeong Jin King ${ }^{\mathrm{a}}$

${ }^{\text {a }}$ Lee Kong Chian Faculty of Engineering and Science, UTAR, Kajang, Malaysia 43000.

b School of Engineering and The Built Environment, Edinburgh Napier University, Edinburgh EH10 5DT, UK.

${ }^{\mathrm{c}}$ Department of Mechanical Engineering, Faculty of Engineering, University of Malaya, Malaysia - 50603.

${ }^{\mathrm{d}}$ Mechanical Engineering Education, Universitas Negeri Sebelas Maret, Jl. Ir. Sutami 36A, Surakarta 57126, Indonesia.

* Corresponding author

Phone: +603-90860288

Fax: $\quad+603-90197062$

E-mail address: bernardsaw81@yahoo.com; sawlh@utar.edu.my

\section{Abstract}

Thermal management system is crucial for a Lithium-ion battery pack as cycle life, driving range of electric vehicle, usable capacity and safety are heavily dependent on the operating temperature. Optimum operating temperature of Lithium-ion battery pack is about $25{ }^{\circ} \mathrm{C}-40{ }^{\circ} \mathrm{C}$. Power availability of the battery pack may differ according to the operating temperature. Although air cooling is the simplest and cheapest cooling solution, the cooling capacity is still limited by the low specific heat capacity. This will cause large variation of temperature of cells across the battery pack. In this study, mist cooling is proposed for battery pack thermal management system. Experiments and numerical simulations are conducted to investigate the thermal performance of conventional dry air cooling and mist cooling. Simulation results are then validated with the experimental data. The simulation results show that mist cooling can offer lower and more uniform temperature distribution compared to dry air cooling. Mist cooling with mass flow rate of $5 \mathrm{gs}^{-1}$ and $3 \%$ mist loading fraction is sufficient to ensure the surface temperature of the 
battery module maintained to below $40^{\circ} \mathrm{C}$. Therefore, mist cooling is a potential solution for the thermal management system of Lithium-ion battery pack.

Keywords: Li-ion battery; mist cooling; air cooling; CFD analysis; battery temperature 


\section{Introduction}

The growing awareness of environmental issues and limited resources of fossil fuels has generated considerable interest in pursuing an alternative, renewable energy source to overcome the global energy crisis and stringent emission legislation. On top of that, recognizing the physical impacts of fossil fuel use on the environment and climate system, it has become a global agenda to develop promising alternative energy sources, which are environmentally acceptable and technically feasible. Of late, Electric Vehicle (EV) has received a great deal of attention in the industries and research works as one of the rising green transportation technologies to reduce over-reliance on fossil fuel applications in the transportation sectors. Unlike conventional vehicles which are powered by diesel or gasoline fuelled internal combustion engines (ICE), EV runs on electric power source with off-board charging. This feature also distinguishes the EV from the hybrid electric vehicles, in which battery power is employed to supplement the ICE without plugged-in convenience. In view of this, EV is targeted as a promising alternative to providing cleaner and greener means of transportation in the near future before fuel cell technology reaches its maturity.

Battery pack is the primary energy source for EV and performance of the EV is greatly dependent on the operation of the battery pack. Nowadays, Lithium-ion (Li-ion) battery is widely used in the EV battery pack due to its high energy and power density, no memory effect, long cycle life, and fast charging capability [1-2]. However, performance of the battery pack is very sensitive to the working temperature. Ideal working temperature range of the Li-ion battery is between $25^{\circ} \mathrm{C}$ to $40{ }^{\circ} \mathrm{C}$ [3]. Reducing the battery temperature will increase the battery’s internal resistance, and subsequently lessen the energy output from the battery. In contrast, increasing the battery temperature will enhance the battery's degradation rate as well as its impedance and this will result in 
a shorter battery cycle life. In extreme conditions, high operating temperature may cause irreversible chemical reactions, leading to the generation of thermal runaway [4-6]. Hence, a thermal management system is desired to maintain the operating conditions of the battery pack at optimum levels as well as to ensure safety and reliability of the battery pack.

The main function of the battery pack thermal management system is to maintain the average temperature of the battery cells at their optimum operating temperature window, in which the variation of the individual cell temperature in the battery pack is less than $5{ }^{\circ} \mathrm{C}[3,7]$. The common types of cooling technology used in these Li-ion battery packs include air cooling, liquid cooling, phase change material (PCM) as well as the mix combinations of them [8-13]. Among all these cooling technologies, air cooling technique, particularly with the use of reciprocating flow, has been employed by Mahamud and Park [14] to investigate its feasibility on the battery pack to enhance temperature uniformity and reduce maximum operating temperature. In comparison to the air cooling method with uni-directional flow, reciprocating air cooling method with reciprocating period of $120 \mathrm{~s}$ is found to be more effective whereby a $72 \%$ reduction in the battery pack's maximum temperature is recorded. Apart from this, it is also observed that the temperature distribution of the battery surface is more uniform when shorter reciprocating period is used. In spite of this, the battery temperature located at the center of the battery pack is always higher as compared to those at both ends. Furthermore, Mi et al. [15] have investigated the thermal performance of the battery pack installed with cooling fin as thermal management system and air is used as a cooling fluid. Finite element analysis results reveal that thermal performance of the battery pack is proportional to the length of the cooling fin. At least $25 \mathrm{~mm}$ of cooling fin length is needed to ensure that the battery pack temperature is maintained below the threshold temperature 
of $40^{\circ} \mathrm{C}$. On the other hand, Vita et al. [16] have used computational fluid dynamic (CFD) simulation to inspect temperature distribution of the Lithium Iron Phosphate battery pack using natural convection, forced air convection and liquid cooling under different C-rates of constant current charging/discharging. A small gap of $2 \mathrm{~cm}$ is reserved in between the battery blocks to function as a cooling channel. It is found that the maximum temperature of the battery cell is increased by $10{ }^{\circ} \mathrm{C}$ for natural convection, and $8{ }^{\circ} \mathrm{C}$ by forced convection using $0.0695 \mathrm{kgm}^{-2} \mathrm{~s}^{-1}$ of cooling air. Besides, variation of temperature within the battery pack is more homogeneous for natural convection as compared to forced convection at the end of the discharging/charging process. Meanwhile, for liquid cooling, a counter-flow cold plate is sandwiched in between the battery blocks to dissipate the heat generated. The final temperature of the battery was only increased by $2.5{ }^{\circ} \mathrm{C}$ when 239 $\mathrm{Lh}^{-1} \mathrm{~m}^{-2}$ of water flow was used. In view of the benefits of liquid cooling, this technique has been adopted by Basu et al. [17] in their three-dimensional electrochemical thermal modeling work to analyze the liquid cooling thermal management system of 18650 battery packs. Aluminum sheets are wrapped around the cylindrical cell to extract the heat generated and dissipate them to the cooling channel at both sides of the battery pack. However, the presence of contact resistance between the cells and aluminum sheet has deterred the heat from being conducted effectively to the cooling channel. As a consequence, hybrid PCM with forced air convection battery thermal management system is proposed to improve the performance of the battery pack [18]. Although conventional PCM can reduce sharp rise in battery temperature, heat absorbed by PCM cannot be dissipated efficiently to the surroundings through natural convection. Hence, a forced convection system is applied to dissipate heat accumulated in the PCM. Numerical and experimental results show that at least $3 \mathrm{~ms}^{-1}$ of cooling air is required to cool the heated battery pack below $45{ }^{\circ} \mathrm{C}$. Aside from liquid cooling technique, heat pipe based battery 
pack thermal management system is also a popular choice due to its advantages of compact design, lightweight and high thermal conductivity as compared to liquid cooling [19-20]. This technique has been adopted by Zhao et al. [19] to cool the pouch cells with the use of ultra-thin heat pipes combined with wet cooling, especially for high current operations. For 1 to 3 C-rates of discharge, temperature increment of the cell is less than $4{ }^{\circ} \mathrm{C}$. The variation of temperature across the battery pack is less than $1.5{ }^{\circ} \mathrm{C}$ and temperature difference across a single cell is $0.5{ }^{\circ} \mathrm{C}$ for a $3 \mathrm{Ah}$ battery pack.

Among all the currently available thermal management systems, air cooling thermal management system is the most preferred cooling option for the automotive manufacturers. This can be attributed to its low operating cost and compact design with good reliability. Conversely, the setbacks of the air cooling system, such as its low cooling capacity, limited flow rate and inhomogeneous temperature distribution in upstream and downstream, have driven the researchers to look for a new type of battery pack thermal management system which is more efficient and yet cost effective.

Evaporative cooling is an emerging cooling technology adopted in the current thermal management system owing to its ability to dissipate high heat flux at reasonable cost [2122]. Coolant droplets absorb excess heat from the heated surface to provide cooling via evaporation. Unlike conventional liquid cooling which requires expensive equipment such as pump, cold plate and heat exchanger, evaporation is an atmospheric process in nature and thus it only requires a minimum amount of energy and cost for operation. Evaporative cooling involving a phase change process from liquid to vapor offers higher heat transfer performance in comparison to a single-phase forced convection process [21]. Latent heat of vaporization of the coolant is the key factor in determining the amount of heat which can be dissipated. As a result, Kumari et al. [23] have investigated the flow and heat transfer characteristics of mist flow through analytical and numerical simulation. 
Up to $97 \%$ reduction in the heat sink thermal resistance can be achieved by replacing forced air convection with evaporating mist flow. Besides, Dhanasekaran and Wang [24] have used CFD simulations to examine the effect of mist/air cooling on the gas turbine efficiency. Cooling enhancement of $20 \%$ is achieved when $2 \%$ wt of mist is injected to the air stream. Furthermore, mist-air film cooling is effective in reducing the vane-wall temperature in a gas turbine by $20 \mathrm{~K}$ to $48 \mathrm{~K}$ with addition of $1 \%$ to $3 \%$ mist ratio [25]. Boundary layer temperature is reduced without affecting the mainstream temperature and boundary layer thickness. Similarly, Kumari et al. [26] have studied the thermal performance of the evaporating mist cooling system analytically and numerically. Droplet size and fraction of mist-fluid are found to be the main parameters affecting the evaporation rate and subsequently the corresponding thermal performance. Despite extensive studies on the phenomenon of mist cooling and droplet to surface impact, the application of mist cooling on the battery pack thermal management system is relatively new to date.

Based on the recent literature search, it is clearly shown that thermal management of the battery pack is crucial in determining the performance of EV. The aim of this study is to evaluate the mist cooling system for a Li-ion battery module. Hence, the objective of this work is twofold. First, the thermal performance and flow field of a dummy cell under forced air convection and mist cooling is evaluated with the application of CFD simulation and the computed results are validated with the experimental measurements. Second, heat generation of the battery is characterized using an accelerating rate calorimeter (ARC) under various C-rates of constant current charging and discharging. Following that, the validated CFD models are applied to investigate the temperature distribution of the cells in the battery module under different cooling configurations. The heat transfer correlation is subsequently derived from the steady state simulation, which is then used to determine 
the thermal performance of the battery module temperature under various transient charging and discharging operations. The organization of the paper is as following: Section two describes the design and analysis of the dummy battery and battery module. CFD modeling procedure is also included in this section. Section three describes the CFD validation results with respect to the experimental data for dummy battery. Consequently, the validated CFD model is applied on the battery module to evaluate the effect of mist cooling for various C-rates of charging and discharging. Besides, the use of aggressive US 06 driving cycle to assess the effectiveness of the mist cooling system for the EV battery pack is also presented in this section. The last section concludes the findings of the current study.

\begin{tabular}{|c|c|}
\hline \multicolumn{2}{|c|}{ Nomenclature } \\
\hline$A_{P}$ & Surface area of the droplet, $\mathrm{m}^{2}$ \\
\hline$C_{D}$ & Drag coefficient \\
\hline$C_{p}$ & Heat capacity, $\mathrm{J} \mathrm{kg}^{-1} \cdot \mathrm{K}^{-1}$ \\
\hline$D_{A B}$ & Mass diffusion coefficient, $\mathrm{m}^{2} \cdot \mathrm{s}^{-1}$ \\
\hline$D_{h}$ & Hydraulic diameter, m \\
\hline$D_{P}$ & Droplet diameter, m \\
\hline$d U / d T$ & Entropy coefficient \\
\hline$d V$ & Volume of a numerical cell, $\mathrm{m}^{3}$ \\
\hline$h$ & Heat transfer coefficient, W.m². $\mathrm{K}^{-1}$ \\
\hline$h_{f g}$ & Latent heat of evaporation, $\mathrm{Jkg}^{-1}$ \\
\hline$h_{m}$ & Mass transfer coefficient, $\mathrm{ms}^{-1}$ \\
\hline$I$ & Current passing through the battery, A \\
\hline$k$ & Thermal conductivity, $\mathrm{W} \cdot \mathrm{m}^{-1} \cdot \mathrm{K}^{-1}$ \\
\hline$L$ & Length of the battery module, $\mathrm{m}$ \\
\hline$m_{v}$ & Mass fraction of vapour \\
\hline$m_{p}$ & Mass of single droplet, $\mathrm{kg}$ \\
\hline$m_{p 0}$ & Initial droplet mass, $\mathrm{kg}$ \\
\hline $\bar{m}_{P}$ & Average droplet mass in the control volume \\
\hline$\dot{m}_{P}$ & Mass flow rate of droplet, kg. $\mathrm{s}^{-1}$ \\
\hline$\Delta m_{p}$ & Total evaporated water vapour in the one-time step, $\mathrm{kg}$ \\
\hline $\mathrm{Nu}$ & Nusselt number \\
\hline$p$ & Pressure, $\mathrm{Pa}$ \\
\hline $\operatorname{Pr}$ & Prandtl number \\
\hline$\dot{q}^{\prime \prime \prime}$ & Volumetric heat source, W.m ${ }^{-3}$ \\
\hline $\operatorname{Re}_{\mathrm{D}}$ & Droplet relative Reynolds number \\
\hline$S_{m}$ & Volumetric mass source, $\mathrm{kg} \cdot \mathrm{m}^{-3} \cdot \mathrm{s}^{-1}$ \\
\hline Sc & Schmidt number \\
\hline Sh & Sherwood number \\
\hline
\end{tabular}




\begin{tabular}{|ll|}
\hline$T$ & Temperature, $\mathrm{K}$ \\
$T_{b}$ & Average temperature of the battery body, $\mathrm{K}$ \\
$u$ & Velocity, $\mathrm{m}^{-1}$ \\
$U$ & Open circuit voltage, $\mathrm{V}$ \\
$\mathrm{V}$ batt & Battery voltage, $\mathrm{V}$ \\
\multicolumn{2}{|c|}{} \\
Greek symbol \\
$\mu$ & Dynamic viscosity, $\mathrm{kg} \cdot \mathrm{m}^{-1} \cdot \mathrm{s}^{-1}$ \\
$\rho$ & Density, $\mathrm{kg} \cdot \mathrm{m}^{-3}$ \\
$\tau$ & Shear stress, Pa \\
& \\
Subscripts & \\
$V$ & Evaporated vapour \\
$P$ & Dispersed fluid \\
\hline
\end{tabular}

\section{Design and analysis of the battery module}

\subsection{Dummy cell test rig and battery module design}

A dummy cell test rig is constructed to validate the numerical simulation results with experimental measurements. The dummy cell test rig consists of a copper rod as dummy battery, with a diameter of $38 \mathrm{~mm}$ and a length of $146 \mathrm{~mm}$ in a Perspex tube. The test rig is used to model the Headway 38120P cylindrical Lithium Iron Phosphate cell with 8 Ah capacity. Specifications of the battery are tabulated in Table 1.

The battery module used in this study consists of six cells arranged in a circular pattern. Voltage of a single cell is $3.2 \mathrm{~V}$, so the total voltage of a battery module is 19.2 V. Battery bodies and terminals are coated with Boron Nitride in order to enhance heat transfer performance as well as to prevent short circuits and corrosion issue [27]. Schematic diagram of the battery module is shown in Fig. 1. Battery module is a sub-unit of a battery pack arranged repeatedly. Therefore, only a battery module is investigated in this study. Joule heat, reversible entropy heat and irreversible heat are the three different types of heat generated in a Li-ion battery [28], as depicted in Eq. 1. The first two terms on the right-hand side of the equation represent the energy losses due to electrochemical polarization. The process is irreversible and hence the value obtained is always positive. 
The last term represents reversible heat generated due to entropy change in the cell and it can be positive or negative.

$$
Q_{g e n}=I\left(U-V_{b a t t}+T_{b} \frac{d U}{d T}\right)
$$

\subsection{Experimental setup}

Experimental testing is conducted on a dummy battery to validate the numerical simulation results. Fig. 2 shows the mist/dry air flow direction and the location of thermocouples attached to the dummy battery. Cartridge heater with a diameter of $6 \mathrm{~mm}$ is inserted in the middle of the copper rod to generate a constant heat of $5 \mathrm{~W}$. The copper rod is located at $0.3 \mathrm{~m}$ from the right end to ensure uniform air flow on the copper rod. Axial fan (SanAce40, Sanyo Denki) is placed on the upper left end of the Perspex tube to supply constant flow rate of dry air. On the other hand, three ultrasonic mist generators are placed on the lower right end of the Perspex tube to supply constant mass flow rate of mist, which is about $440 \mathrm{ml} . \mathrm{h}^{-1}$ for each of the ultrasonic mist generator. The power rating of the ultrasonic mist generator is $2.4 \mathrm{~W}$. The coolant used in this study is distilled water. Surface temperature of the dummy battery is measured using six thermocouples (K-types) attached to different locations using aluminium tape. Three thermocouples are attached in the axial direction and on the two sides of the dummy battery surface as illustrated in Fig. 2. The ambient temperature for the experimental setup is $30{ }^{\circ} \mathrm{C}$. A data acquisition system, namely HP 34970A, is used to record the temperature readings. On the other hand, velocity of the dry air/mist is measured using a hot wire thermo-anemometer (Extech instruments). A differential pressure transducer (Gems sensor, 5266 series) is connected to the pressure taps at the inlet and outlet of the test rig to measure the pressure drop across the test rig. All the tests are repeated three times and the average value is taken. Next, experimental results are compared with the CFD results under similar flow conditions. Lastly, the validated results are extended to investigate the thermal response 
of mist cooling on a battery module. The specific heat capacity of the 38120 cell is measured using an adiabatic accelerating rate calorimeter (THT ARC). The charging and discharging of the battery is performed using a battery cycler (Maccor Instrument 4000), while the heat generation rate of the battery during charging and discharging is measured using an accelerating Rate Calorimeter (ARC). The heat generation rate of the battery during charging is measured across three different C-rates, namely 1, 3 and 5 C-rates, while the heat generation rate of the battery during discharging is measured across 1,2 , and 3 C-rates.

\subsection{Numerical procedures}

The CAD models of the test rig and battery module are constructed using commercial CAD software Solidworks 2016 while commercial CFD software, namely ANSYS-CFX, is used as an accompaniment for the experimental study. The CFD analysis is essential in order to gain insight into the flow field and thermal response, which are difficult to observe in the experiment. Here, several assumptions are made to model the fluid flow and heat transfer in the test rig as well as battery module. These include:

i. Steady state flow condition;

ii. Incompressible flow;

iii. No thermal energy source in the fluid,

iv. Constant thermo-physical properties; and

v. Negligible heat loss due to radiation and natural convection [29].

\subsubsection{Governing equations}

In this section, the CFD governing equations applied to resolve the three-dimensional forced air convection and mist cooling cases are presented.

\subsubsection{Transport equations for mist cooling}


Numerical modelling of the flow field and thermal behaviour of the mist cooling involving two-phase flow is a complex transport process. Mist flow comprises air, liquid droplets as well as vapour phase of the evaporated droplet, and the composition of the flow stream is dependent on the droplet evaporation [23]. The momentum, continuity, energy and species equations are coupled with interaction terms between disperse and continuous fluids. The transport equations for mist flows are solved using the dispersed fluid model in ANSYS CFX [30]. In the simulations, air-liquid vapour mixture is treated as continuous fluid and the liquid droplet is treated as dispersed phase. Transport equations such as continuity, momentum and energy used for mist cooling are described in Eq. (2) to Eq. (7), respectively.

Continuity equation:

$$
\frac{\partial}{\partial x_{i}}\left(\rho u_{i}\right)=S_{m}
$$

$\mathrm{S}_{\mathrm{m}}$ is the source term of mass that accounts for the interactions between the continuous fluid and dispersed fluid, and it can be represented by the following equation:

$S_{m}=\frac{\Delta m_{p}}{m_{p 0}} \frac{\dot{m}_{p 0}}{d V}$

Momentum equation:

$\frac{\partial}{\partial x_{i}}\left(\rho u_{i} u_{j}\right)=-\frac{\partial P}{\partial x_{i}}+\frac{\partial \tau_{i j}}{\partial x_{j}}+F_{i}$

$P$ is the pressure, $\tau$ is the extra stress tensor and $F$ is the source term of momentum that accounts for the interaction between continuous fluid and dispersed fluid, in which

$$
F_{i}=\sum\left(\frac{18 \mu C_{D} R e_{D}}{24 \rho_{p} D_{p}^{2}}\left(u_{P, i}-u_{i}\right)\right) \dot{m}_{P} \Delta t
$$

\section{Energy equation:}

$$
\frac{\partial}{\partial x_{i}}\left(\rho c_{p} u_{i} T\right)=\frac{\partial}{\partial x_{i}}\left(k_{i} \frac{\partial T}{\partial x_{i}}\right)+\dot{q}^{\prime \prime \prime}
$$


$c_{p}$ is the heat capacity, $k$ is the thermal conductivity and $\dot{q}^{\prime \prime \prime}$ is the source term of energy that accounts for the interaction between the continuous fluid and dispersed fluid, which is defined as:

$\dot{q}^{\prime \prime \prime}=\left[\frac{\bar{m}_{p}}{m_{p 0}} C_{p, P} \Delta T_{p}+\frac{\Delta m_{p}}{m_{p 0}}\left(-h_{f g}+\int_{T_{r e f}}^{T_{p}} c_{p, v} d T\right)\right] \frac{\dot{m}_{p 0}}{d V}$

Sensible heating of the liquid droplet, latent heat required for the evaporation process and sensible heating of the water vapour generated are included in the energy exchange term.

\subsubsection{Transport equation for water vapour}

The transport equation for water vapour is represented in Eq. (8).

$$
\frac{\partial}{\partial x_{i}}\left(\rho u_{i} m_{v}\right)=\frac{\partial}{\partial x_{i}}\left(\rho D_{A B} \frac{\partial m_{v}}{\partial x_{i}}\right)+S_{m}
$$

where $m_{v}$ is the water vapour mass fraction.

\subsubsection{Governing equations for liquid droplet evaporation}

The expression for liquid droplets evaporation is given in Eq. (9):

$\frac{d m_{p}}{d t}=-h_{m}\left(\rho_{v, s}-\rho_{v}\right) A_{p}$

in which mass transfer coefficient $h_{m}[26]$ is defined as:

$$
\begin{aligned}
& S h=\frac{h_{m} D_{p}}{D_{A B}}=2.0+0.6 R e_{D}^{0.5} S c^{1 / 3} \\
& \frac{d u_{p}}{d t}=\frac{18 \mu}{\rho_{p} D_{p}^{2}} \frac{C_{D} R e_{D}}{24}\left(u-u_{P}\right)
\end{aligned}
$$

The relative Reynolds number is calculated with equations below:

$$
\begin{aligned}
& R e_{D}=\frac{\rho D_{p}\left|u_{p}-u\right|}{\mu} \\
& m_{P} C_{P, p} \frac{d T_{P}}{d t}=h A_{P}\left(T-T_{P}\right)+h_{f g} \frac{d m_{P}}{d t}
\end{aligned}
$$

Heat transfer coefficient $h$ [26] is defined as:

$$
N u=\frac{h D_{p}}{k}=2.0+0.6 \operatorname{Re}_{D}^{0.5} \operatorname{Pr}^{1 / 3}
$$


$T$ is the temperature of the local continuous fluid. Drag force that is acting on the droplet will affect the momentum of the droplet which is caused by relative movement between droplet and continuous fluid. The energy equation depicted in Eq. (13) assumed no spatial temperature distribution within the droplet. Convective heat transfer and evaporation process play important roles in determining the energy of the droplet. Sherwood and Nusselt numbers account for diffusive and also convective processes involving the mass and heat transfer between continuous and dispersed fluid. In this study, last term on the right hand side in Eq. (10) and Eq. (14) only have a minor contribution and predominant transport process is diffusion.

\subsubsection{Turbulence flow equations}

The standard k- $\varepsilon$ turbulence model is chosen to simulate the flow conditions in the test rig and battery module [30]. The transport equations are represented by Eq. (15) and Eq. (16).

$$
\begin{aligned}
\rho_{f} \frac{\partial k}{\partial \tau}+\rho_{f} \nabla(\mathbf{u} k) & =\nabla\left(\frac{\mu_{t}}{\sigma_{k}} \nabla k\right)+G_{k}-\rho_{f} \varepsilon+S_{k} \\
\rho_{f} \frac{\partial \varepsilon}{\partial \tau}+\rho_{f} \nabla(\mathbf{u} \varepsilon) & =\nabla\left(\frac{\mu_{t}}{\sigma_{\varepsilon}} \nabla \varepsilon\right)+C_{1 \varepsilon} \frac{\varepsilon}{k} G_{k}-C_{2 \varepsilon} \rho_{f} \frac{\varepsilon^{2}}{k}+S_{\varepsilon}
\end{aligned}
$$

$k$ is the turbulence kinetic energy, whereas $\varepsilon$ is the turbulence dissipation rate, $\sigma_{k}=$ 1.0 and $\sigma_{\varepsilon}=1.3$ are the turbulent Prandtl number for $k$ and $\varepsilon$, respectively. $\mathrm{C}_{1 \varepsilon}=1.52$, $\mathrm{C}_{2 \varepsilon}=1.92$ and $\mathrm{C}_{\mu}=1.92$ are the suggested experimental constants [31-32]. $S_{k}$ and $S_{\varepsilon}$ are the source terms for $k$ and $\varepsilon$, respectively. $\mu_{t}$ and $G_{k}$ are represented by Eq. (17) and Eq. (18), respectively.

$$
\begin{aligned}
& \mu_{t}=\rho_{f} C_{\mu} k^{2} / \varepsilon \\
& G_{k}=\mu_{t}\left[\nabla \mathbf{u}+(\nabla \mathbf{u})^{T}\right] / \nabla \mathbf{u}
\end{aligned}
$$

\subsubsection{Transient state energy equation of the battery}

Lastly, the energy equation of the battery under transient mode is given by: 


$$
m C_{p} \frac{d T_{c}}{d t}=\nabla\left(\lambda_{c} \nabla T_{c}\right)+Q_{g e n}
$$

\subsubsection{Numerical setups and boundary conditions}

A steady state three dimensional conjugate heat transfer simulations are conducted to investigate the flow field and heat transfer performance of the test rig and battery module. A uniform heat generation of $5 \mathrm{~W}$ (corresponding to average heat generated at 3

C-rate of charging) is assigned to the copper rod and battery [33]. Isotropic thermal conductivity is used to model the dummy cell test rig which is constructed using copper rod. The main purpose of the dummy cell test rig is used to validate the numerical model of the mist cooling system. On the other hand, anisotropic thermal conductivity as depicted in Table 1 is employed to model the conduction of the six batteries in the battery module. Since heat travels faster in the axial direction as compared to that in the radial direction. Low thermal conductivity in the radial direction will lead to significant differences in the temperature distribution in the battery and subsequently produce higher overall temperature as well as large temperature gradient across the battery. Hence, it is important to model the anisotropic thermal conductivity of the battery in the CFD simulation [34-35]. Hybrid meshing technique is used to discretize the test rig and battery module using ANSYS ICEM CFD 17.1. The cooling medium for dry air cooling case is air ideal gas. On the other hand, the cooling mediums for mist cooling case are air ideal gas, water vapour and distilled water. Mass flow boundary condition with medium turbulence intensity of $5 \%$ is assigned to the inlet of the test rig and battery module [30]. Next, pressure boundary condition is assigned to the outlet of the test rig and battery module. Inlet fluid temperature is taken as $30{ }^{\circ} \mathrm{C}$. Perspex tube of the test rig and casing of the battery module are specified as non-slip wall and adiabatic wall boundary conditions, assuming no heat loss from the test rig and battery module. The initialization condition for the computational domain is 1 atm pressure. Boundary conditions of the 
battery module used in the CFD analysis is illustrated in Fig. 3, with details provided in Table 2. All CFD simulation cases are conducted with high resolution scheme and first order advection scheme to obtain accurate results. Tight convergence criteria with root mean square residual of $1.0 \times 10^{-6}$ are applied on the continuity, momentum and energy equations.

\subsubsection{Computational grids}

Grid sensitivity analysis is first conducted to make sure simulations results are not affected by mesh size and the relative discrepancy of the results (temperature and pressure drop) is less than $5 \%$. Three different types of mesh size are generated, i.e. Mesh-1 (coarse) with 4,919,835 elements, Mesh-2 (medium) with 5,497,946 elements and Mesh3 (fine) with 7,379,809 elements. The grid independent test is conducted under cooling air velocity of $1 \mathrm{~ms}^{-1}$, and the results are tabulated in Table 3. As shown in Table 3, the relative percentages of deviation in the computed average temperature between Mesh-1 and Mesh-2, Mesh-2 and Mesh-3 are $0.51 \%$ and $0.82 \%$, respectively. On the other hand, the difference in the pressure drop calculated by Mesh-2 and Mesh-3 is recorded at about $3 \%$. This shows that Mesh-3 with 7,379,809 elements is sufficient to model the test rig as grid independence has been achieved. Same grid sensitivity analysis procedure is also applied on the battery module to ensure that all relative percentage of deviations between the predictions by Mesh- 1 and Mesh-2, Mesh-2 and Mesh 3 is less than $5 \%$. It is found that Mesh-3 with 5,325,389 elements for the battery module has reached grid independent and is ready to be used in the subsequent simulation work. All CFD simulations are conducted on the workstation with Intel i7-6800K, 3.40 GHz CPU and 64 GB. The total computational duration is approximately 12 hours $10 \mathrm{~min}$.

During the charging/discharging process the battery may not reach a thermal equilibrium state. The condition is worsen especially during fast charging or high C-rate 
of discharging, when the charging duration is very short and heat generation is more intensive. Therefore, it is more practical to conduct three-dimensional transient simulation to investigate the thermal response of the cell under various cooling condition by considering transient heat generation of the battery. However, this type of simulation is very complicated and the solution requires extensive computational resources due to complex air flow dynamic and conjugate heat transfer process especially for large battery pack. The computational duration for a transient simulation case is significantly greater than that for a steady-state simulation and the resultant data file size may be built up to unacceptable level and it is impractical for the current study. Therefore, steady state simulation is conducted in this study to assess the thermal performance of the battery module and optimize the battery module design to ensure the variation of battery temperature is as uniform as possible. Next, the correlations of Nusselt number to Reynolds number and Prandtl number which are developed based on the steady-state simulations are used to evaluate the effectiveness of mist cooling on the battery module in transient state. The effective heat transfer coefficient derived from steady-state simulation is assigned to describe the forced convection phenomenon at the battery surface. This simplified method assumes that only minor change in the mist temperature and only small temperature variation present among the battery. This method which is derived from the previous research work [9] would be able to provide a quick assessment on the thermal management system performance without conducting a comprehensive transient simulation.

\subsection{Data processing}

Heat transfer from batteries to the cooling air in the battery module can be expressed as:

$$
\dot{Q}_{\text {total }}=\dot{Q}_{c o n v}+\dot{Q}_{\text {rad }}+\dot{Q}_{\text {evap }}
$$




$$
\dot{Q}_{\text {conv }}=\dot{m} C_{P}\left(T_{\text {out }}-T_{\text {in }}\right)+\dot{m}_{p} h_{f g}
$$

Mass flow rate, $\dot{m}$, of the cooling fluid is calculated based on the mean velocity of the air supplied by the axial fan, $V_{\infty}[9]$ :

$$
\dot{m}=\rho A_{d u c t} V_{\infty}
$$

Here, radiation heat loss of the battery module is neglected. Hence, the heat transfer from the batteries can be reduced to equation below:

$$
\dot{Q}_{\text {total }}=\dot{Q}_{c o n v}
$$

The rate of convective heat loss from batteries, $\dot{Q}_{c o n v}$, can be expressed in equation below:

$$
\dot{Q}_{c o n v}=\bar{h} A_{\text {ext }}\left[\bar{T}_{s}-\left(\frac{T_{\text {out }}+T_{\text {in }}}{2}\right)\right]
$$

Steady state heat dissipated through cooling fluid is equal to the heat loss from the battery. The average convective heat transfer coefficient, $\bar{h}$, can be written as:

$$
\bar{h}=\frac{\dot{Q}_{\text {conv }}}{A_{\text {ext }}\left[\bar{T}_{s}-\left(\frac{T_{\text {out }}+T_{\text {in }}}{2}\right)\right]}
$$

Reynolds number $(R e)$ for the cooling fluid is expressed in Eq. 26 while Nusselt number $(\mathrm{Nu})$ of the battery module are calculated using Eq. 27:

$$
\begin{aligned}
& R e=\frac{\rho V_{\infty} D}{\mu} \\
& N u=\frac{h D}{k}
\end{aligned}
$$

$\mathrm{Nu}$ derived from the CFD simulation is correlated with the $R e$ for different flow rate of cooling fluid. Coefficient $A$, power of $m$ and $n$ are determined through least-meansquares fit. The correlation is then used to estimate the change in the average surface temperature of the batteries under various C-rates of charging.

$$
N u=A \cdot \operatorname{Re}^{m} \cdot \operatorname{Pr}^{n}
$$

The friction factor, $f$, is calculated using Eq. 29.

$$
f=\frac{\Delta P}{\frac{1}{2} \rho u^{2} \frac{L}{D_{h}}}
$$


Correlation of $f$ with $R e$ for different flow rates of cooling fluid is defined in Eq. 30.

Coefficient $A$ and power of $m$ are determined through least-mean-squares fit.

$$
f=A \cdot R e^{m}
$$

\section{Results and discussion}

\subsection{Specific heat capacity and heat generation of battery}

Accelerating rate calorimeter is used to measure the specific heat capacity and heat generation of the battery. Fig. 4 and Fig. 5 illustrate the measurements of heat generated from the battery using an ARC for constant current charging and discharging. At state of charge of about $90 \%$ for constant current charging, the heat generated from the battery is increased momentarily. Similar trend is also observed for the constant current discharging. As shown in Fig. 4, average heat generated from the battery at 1, 3 and 5 Crates of charging are about $0.84 \mathrm{~W}, 4.03 \mathrm{~W}$ and $9.48 \mathrm{~W}$, respectively. On the other hand, average heat generated from the battery for 1 to 3 C-rates of discharging are about 1.35 W, 3.64 W and 5.57 W, respectively as illustrated in Fig. 5.

Fig. 6 and Fig 7 demonstrate the temperature rise of the battery skin in the adiabatic calorimeter during constant current charging and discharging, respectively. As shown in Fig .6, the maximum temperature increments of the battery during adiabatic charging condition of 1,3 , and $5 \mathrm{C}$-rates are about $7.3{ }^{\circ} \mathrm{C}, 14.4{ }^{\circ} \mathrm{C}$ and $18.8{ }^{\circ} \mathrm{C}$, respectively. On the other hand, maximum temperature increments of $9.6{ }^{\circ} \mathrm{C}, 13.9{ }^{\circ} \mathrm{C}$ and $16.5{ }^{\circ} \mathrm{C}$ are obtained during adiabatic discharging condition of 1, 2 and 3 C-rates, respectively. Under ambient temperature of $30{ }^{\circ} \mathrm{C}$, if the battery pack is subjected to $3 \mathrm{C}$ rate of constant current charging and discharging in an adiabatic condition, the battery pack temperature may reach $44.4{ }^{\circ} \mathrm{C}$ and $46.5{ }^{\circ} \mathrm{C}$, respectively. This will severely shorten the cycle life of the battery under prolong operation without any cooling system integrated into the battery 
pack. This indicates that an active thermal management system is necessary to extend the cycle life of the battery and optimize the battery performance.

Specific heat capacity of the battery measured in the ARC is about $998 \mathrm{Jkg}^{-1} \mathrm{~K}^{-1}$. Uncertainty analysis suggested by Moffat [37] is performed to determine the average uncertainty measurement of the specific heat capacity. It is found that the average uncertainty measurements of the battery specific heat capacity and battery temperature are about $2.43 \%$ and $1.03 \%$, respectively. On the other hand, the average uncertainties of the heat generation for various C-rates of charging and discharging are about $3.31 \%$ and $3.21 \%$, respectively.

\subsection{Dummy cell test rig}

\subsubsection{Forced air convection}

Contemporary, convective heat transfer with air remains the most favourable choice as a thermal management system for Li-ion battery pack. Maximum temperature and temperature variation across the battery pack are the two main parameters in the thermal management system design. Maximum operating temperature of the battery must be less than $40{ }^{\circ} \mathrm{C}$ and no less than $25{ }^{\circ} \mathrm{C}$. In addition, temperature uniformity across the battery pack must be less than $5{ }^{\circ} \mathrm{C}$. Comparison between the numerical modelling and experimental results on the average surface temperature of the dummy battery under different dry air velocities is presented in Fig. 8. It is observed that, the change on the average surface temperature of the dummy battery is reduced with increasing dry air velocity. Besides, dry air flow rate of $11.2 \mathrm{gs}^{-1}$ is found to be sufficient to maintain the average temperature of the dummy cell below $40{ }^{\circ} \mathrm{C}$. The average relative deviation between the experimental and simulation results is approximately $4.42 \%$. The simulation

results are in good agreement with the experimental measurements as the relative deviation obtained is less than $5 \%$. 
In addition, the average variation of temperature across the battery surface measured in the experiment is about $0.4{ }^{\circ} \mathrm{C}$. On the other hand, the average variation of temperature across the battery surface obtained in the simulation is about $0.3{ }^{\circ} \mathrm{C}$. The average relative error is about $8.6 \%$. As the temperature variation across the cell is considerably small, hence the experimental results is deemed to be acceptable as compared to the simulation data.

Temperature contour plot of the dummy battery under dry air flow rate of 11.2 gs $^{-1}$ is shown in Fig. 9. As shown in Fig. 9, the variation of temperature distribution across the cell is less than $0.5^{\circ} \mathrm{C}$ and the temperature is uniformly distributed. This is due to high thermal conductivity of the dummy battery. Apart from that, only $1{ }^{\circ} \mathrm{C}$ of temperature difference is captured between the simulated and measured results. The difference is negligibly small and thus it can be concluded that good agreement has been achieved in this case. Based on the simulation results, correlation of $N u$ versus $R e \cdot P r$ is derived through regression analysis and can be expressed as Eq. 31 in Table 4. For forced air convection, Prandtl number is taken as 0.73 and Prandtl number power is taken as of 0.33 [36].

On the other hand, variation of $f$ with $R e$ for the dummy cell test rig extracted from the simulation and experimental results is illustrated in Fig. 10. The maximum relative error of the experimental and simulation results is about $4.48 \%$. It is also shown that the simulation results is correlate well with the experimental data.

\subsubsection{Mist cooling}

The use of liquid as a heat transfer medium offers huge advantages in the thermal management owing to its superior thermal properties compared to air. Among all, the cooling technique involving phase change of liquid is of particular interest as it is capable to dissipate large amount of heat in comparison to that of a single phase cooling. A two- 
phase mixture of fine dispersed liquid droplets is introduced into the air stream to cool the heated target during the mist cooling process. In this case, liquid droplets will be evaporated as they flow downstream by absorbing heat from the surrounding air. Heat absorption capacity of the mist is relatively higher than that of the dry air cooling. Specific heat capacity of dry air is about $1003.5 \mathrm{Jkg}^{-1} \mathrm{~K}^{-1}$, whereas specific heat capacity of distilled water is about $4181.3 \mathrm{Jkg}^{-1} \mathrm{~K}^{-1}$. As compared to dry air cooling, high specific heat capacity of the air-mist enables the cooling fluid to retain the cooling capacity steadily from upstream to downstream. This will reduce the streamwise temperature gradient and it is particularly useful for battery pack cooling which requires minimum variation of temperature and yet without scarifying the cost and cooling effectiveness. In the mist cooling system, heat removal does not rely on direct contact of liquid droplets with a heated surface. Therefore, mist cooling is fundamentally different from the spray cooling technology, which involves impingement and evaporation of liquid droplets on the hot surface. Fig. 11 illustrates the evolution of average temperature of the dummy battery under mist cooling with constant $0.37 \mathrm{gs}^{-1}$ of mist flow. From the simulation and experimental results, it is observed that bulk mist flow rate of $7.5 \mathrm{gs}^{-1}$ is sufficient to maintain the surface temperature of dummy battery below $40{ }^{\circ} \mathrm{C}$. The temperature variation of the dummy battery recorded in the experiment is about $1.7^{\circ} \mathrm{C}$. A temperature difference of $2.2^{\circ} \mathrm{C}$ between experimental measurements and simulation results is obtained when bulk mass flow rate of $3.7 \mathrm{gs}^{-1}$ is applied. It is also observed that the thermal performance for $11.2 \mathrm{gs}^{-1}$ of mist cooling is lower than that of the simulation results. This may be attributed to the accumulation of mist on the dummy battery and subsequently lowers the temperature of the heated surface. Besides, flow obstruction by the thermocouple wires may also lead to above phenomenon. The average relative error between the simulated and experimental temperature measurement is about $2.80 \%$ agree 
well with the simulation results. Temperature contour plot of the dummy battery under mist cooling with bulk mist flow rate of $7.5 \mathrm{gs}^{-1}$ is shown in Fig. 12. The variation of temperature across the dummy battery surface obtained from the CFD results is only $0.5^{\circ} \mathrm{C}$. Correlation of $\mathrm{Nu}$ versus $\mathrm{Re} \cdot \mathrm{Pr}$ for mist cooling is expressed in the Eq. 32 in Table 4 while the Prandtl number is taken as 0.77 .

Average variation of temperature across the battery surface measured in the experiment for mist cooling is about $1.3{ }^{\circ} \mathrm{C}$. On the other hand, average variation of temperature across the battery surface obtained in the mist cooling simulation is about $0.4{ }^{\circ} \mathrm{C}$. The average relative error is significant, which is about 71.4 As mentioned before, this may be due to the accumulation of mist on the dummy battery caused by gravity effect flow obstruction by thermocouple wires. Although the average relative error obtained is high, variation of temperature recorded is always less than $1{ }^{\circ} \mathrm{C}$.

In addition, development of $f$ with respect to different mass flow rates of mist cooling for the dummy cell test rig is demonstrated in Fig. 13. The maximum relative deviation between the experimental and simulation results is about $6.27 \%$. Hence it can be concluded that the simulation results are in good agreement with the experimental data.

\subsection{Battery module}

\subsubsection{Forced air convection}

The thermal response of the battery module subjected to various flow rates of cooling air is examined in this study. Similar to the previous section, the battery module consists of six batteries arranged in a circular orientation, as illustrated in Fig. 1. The results are shown in Fig. 14. A decreasing trend in the average surface temperature of the battery obtained when the mass flow rate increases from $10 \mathrm{gs}^{-1}$ to $150 \mathrm{gs}^{-1}$. On the other hand, variation of the battery surface temperature with respect to the mass flow rate of cooling air is shown in Fig. 15. Similar trend is obtained in which the variation of the battery 
surface temperature decreases with increasing flow rate. The drop is apparent especially when mass flow rate varies from $10 \mathrm{gs}^{-1}$ to $90 \mathrm{gs}^{-1}$. On the contrary, the mass flow rate has little impact on the average surface temperature of the battery when it is greater than $90 \mathrm{~s}^{-1}$. It is also found out that, $90 \mathrm{gs}^{-1}$ of cooling air is required to maintain the maximum surface temperature of the battery below $40{ }^{\circ} \mathrm{C}$. However, the variation of temperature within the battery itself is approximately $6.9^{\circ} \mathrm{C}$, which already exceeds the optimum variation of temperature limit of the Li-ion battery $\left(<5^{\circ} \mathrm{C}\right)$. Therefore, about $150 \mathrm{gs}^{-1}$ of cooling air is required in order to achieve temperature variation which is less than $5{ }^{\circ} \mathrm{C}$. Temperature contour plot of the battery module under forced convection cooling with mass flow rate of $150 \mathrm{gs}^{-1}$ is illustrated in Fig. 16. Thermal response trend in Fig. 14 and Fig. 15 also implies that continuous increment in the mass flow rate of cooling air is not an effective method to reduce the battery temperature. In addition, increasing cooling air flow rate will induce extra noise, increase power consumption and reduce the power availability of the EV as shown in the fan power consumption plot in Fig. 17. Based on the results shown in Fig. 17, about $37.3 \mathrm{~W}$ of fan power is required to cool the battery temperature below $40{ }^{\circ} \mathrm{C}$.

The variation of $f$ with respect to $R e$ for the battery module obtained in the threedimensional conjugate heat transfer analysis is shown in Fig. 18. It can be observed that friction factor decreases with $R e$, which indicates that the resistance of the cooling air in the battery module is increased. Based on the simulation results obtained, correlation of $\mathrm{Nu}$ with $\mathrm{Re} \cdot \mathrm{Pr}$ as well as the correlation of $f$ with $R e$ can be expressed by Eq. 33 in Table 4 and Eq. 34, respectively.

$$
f=0.9438 R e^{-0.057}
$$




\subsubsection{Mist cooling}

Three different cases corresponding to the different inlet mist loading fractions are examined in this study. The three inlet mist loading fractions used for the analysis are 1 $\%, 3 \%$ and $5 \%$ of the bulk inlet mass flow rate of the battery module. The cooling enhancement results upon the introduction of mist cooling on the battery module are illustrated in Fig. 19; while the variation of battery temperature in the battery module is shown in Fig. 20. It can be seen that maximum temperature of the batteries have been reduced tremendously with an introduction of the mist cooling. It found that, $20 \mathrm{gs}^{-1}$ of bulk inlet mass flow rate with $1 \%$ mist loading fractions, $5 \mathrm{gs}^{-1}$ of bulk inlet mass flow rate with $3 \%$ mist loading fractions or $5 \mathrm{gs}^{-1}$ of bulk inlet mass flow rate with $5 \%$ mist loading fractions is sufficient to maintain the batteries temperature below $40{ }^{\circ} \mathrm{C}$. However, the variation of temperature for $1 \%$ mist loading fractions at $20 \mathrm{gs}^{-1}$ is recorded at about $8.1^{\circ} \mathrm{C}$, which is greater than the maximum allowable temperature variation limit. For $3 \%$ of mist loading fraction case, the temperature variation is about $4.8^{\circ} \mathrm{C}$ for 5 gs $^{-}$

${ }^{1}$; whereas for $5 \%$ of mist loading fraction case, the temperature variation is about $2.8{ }^{\circ} \mathrm{C}$ for $10 \mathrm{gs}^{-1}$. Hence, higher percentage of mist loading fractions is desired to achieve more uniform temperature distribution. It is thus concluded that replacing dry air cooling with mist cooling can lead to substantial reduction in the maximum battery temperature and eventually result in a more uniform temperature distribution. Temperature contour plot of the battery module under $3 \%$ of mist loading fractions with mass flow rate of $5 \mathrm{gs}^{-1}$ is illustrated in Fig. 21. The terminal of the battery is located inside the Perspex holder and is restricted from the convection cooling. Therefore, the temperature of the batteries terminals is higher than the battery body. In order to have $3 \%$ mist loading, about 2 mist generators is needed. The power consumption of the mist generators is about $4.8 \mathrm{~W}$. On the other hand, the fan power consumption for forced air cooling is approximately 37.3 
W, which is significantly higher than that of the mist generator. From the energy consumption point of view, mist cooling consumes less energy as compared to the forced air cooling to achieve similar cooling performance.

Temperature contour plot of the battery internal temperature in the battery module under $3 \%$ mist loading fractions and $5 \mathrm{gs}^{-1}$ of mass flow rate is presented in Fig. 22. The highest temperature region is located at the center region of the battery. This can be attributed by the anisotropic nature of layered active material inside the battery. About $5.3{ }^{\circ} \mathrm{C}$ of temperature gradient is observed in the radial direction of the battery. This indicates that active material region has a poor thermal conductivity. Porous electrodes and separators are poor thermal conductors as opposed to the current collectors in the battery which is made of copper and aluminum. The separator is made of polymer and its main role is to isolate the anode and cathode layers, providing a transport medium for the Lithium-ion. Poor thermal conductivity of the separator will prevent the dissipation of heat generated in the battery to the external environment effectively.

The evolution of the $f$ with $R e$ for the battery module under mist cooling is shown in Fig. 23. Mist cooling is seen to possess a similar trend with the dry air cooling, whereby friction factor decreases with $R e$. Based on the simulation results obtained, the correlations of $\mathrm{Nu}$ with Re for mist loading fractions of $1 \%, 3 \%$ and $5 \%$ can be expressed by Eq. 35 - Eq. 37 in Table 4. On the other hand, correlations of $f$ with $R e$ for mist loading fractions of $1 \%, 3 \%$ and $5 \%$ can be expressed by Eq. 38 - Eq. 40, respectively.

$1 \%$ of mist loading fraction

$$
f=47.914 R e^{-0.42}
$$

$3 \%$ of mist loading fraction

$$
f=566.06 R e^{-0.626}
$$

$5 \%$ of mist loading fraction 


$$
f=1976.4 R e^{-0.722}
$$

It is clearly shown that the $\mathrm{Nu}$ for the mist cooling is higher than that of the dry air cooling. The bulk mean temperature of the continuous fluid is lower than that of the dry air cooling. This is contributed by the presence of the water mist droplets and water vapor in the air stream. Specific heat capacity of the continuous fluid has been elevated as compared to dry air cooling. This has resulted in a large temperature gradient (battery surface and bulk mean temperature) available for heat transfer, especially in the downstream of the battery module. The cooling capacity of the cooling fluid can be maintained almost constant from upstream to downstream and this enhances the overall heat dissipation capacity as compared to dry air cooling.

\subsubsection{Transient simulation for mist cooling}

Simplified transient simulation is conducted to evaluate the temperature rise of the battery module under different C-rates of charging and discharging. Transient heat generation of the battery is governed by Eq. 19, which is obtained through the ARC measurement of the cell under adiabatic condition and is assigned to the battery domain as a heat source. Meanwhile, the heat transfer coefficient as in Eq. 36 is assigned to the battery surfaces as an effective convective heat transfer boundary. The mist loading is 3 $\%$ and flow rate is 5 gs $^{-1}$. The simulations are conducted for different C-rates of charging and discharging using the heat generation results extracted from the ARC, as shown in Fig. 4 and Fig. 5. The average surface temperatures of the battery for different C-rates of charging and discharging are plotted in Fig. 24 and Fig. 25, respectively. The simulation

results demonstrate an increasing trend in the average surface temperature over the charging or discharging duration. As shown in Fig. 24, final predicted surface temperature of the battery is about $31.0^{\circ} \mathrm{C}, 34.5^{\circ} \mathrm{C}$ and $38.2^{\circ} \mathrm{C}$ for $1 \mathrm{C}, 3 \mathrm{C}$ and $5 \mathrm{C}$-rates of charging, respectively. On the other hand, final predicted surface temperature of the battery for 1 
C, 2 C and 3 C-rate of discharging is about $32.1{ }^{\circ} \mathrm{C}, 34.6{ }^{\circ} \mathrm{C}$ and $36.2^{\circ} \mathrm{C}$, respectively as shown in Fig. 25. As compared to the battery module without thermal management system, overall surface temperature of the battery is reduced to the optimum operating temperature limit of the Li-ion battery $\left(25^{\circ} \mathrm{C}-40{ }^{\circ} \mathrm{C}\right)$ using mist cooling system. This simulation results further confirm that mist cooling is a potential solution for the development of the Li-ion battery thermal management system.

\subsubsection{Thermal response of the battery module under US06 driving cycle}

Modelling of the battery pack is based on the previous studies to provide a similar power capacity for the converted EV using Hyundai Trajet [28, 33]. Mist cooling with mist loading of $3 \%$ and mass flow rate of $5 \mathrm{gs}^{-1}$ is used to provide cooling effect to the battery pack when the battery temperature rises to above $35^{\circ} \mathrm{C}$. The battery pack consists of five modules connected in series and another five modules connected in parallel. Each module is constructed using six pieces of 38120 cells. Each module in the battery pack is subjected to the same amount of mist cooling. Since the battery module is assumed to be identical in this case, hence it is sufficient to be used to study the thermal response of a battery module. US06 driving cycle is the most aggressive driving cycle, in which more energy is being charged and discharged from the battery pack and thus more heat is being generated. Therefore, it is suitable to be used to investigate the effectiveness of mist cooling system.

Thermal response of the battery temperature under US06 driving cycle is shown in Fig. 26. The battery pack is subjected to repeating US06 driving cycle until the total voltage of the battery pack is below $64 \mathrm{~V}$. The battery pack is able to complete 5.16 cycles and deliver power for $3096 \mathrm{~s}$. At the end of the cycle, the average temperature of the battery in the module could reach $44.2{ }^{\circ} \mathrm{C}$ without any thermal management system installed on the battery pack. On the other hand, when the battery pack is subjected to 3 
$\%$ of mist loading and mass flow rate of $5 \mathrm{gs}^{-1}$, the surface temperature of the battery at the end of the driving cycle is about $36.5{ }^{\circ} \mathrm{C}$ and is able to maintain the surface temperature of the battery far below $40{ }^{\circ} \mathrm{C}$. Therefore, it can be concluded that, mist cooling is an efficient thermal solution for the EV battery pack.

\section{Conclusions}

A three dimensional conjugate heat transfer analysis is conducted to investigate the performance of a novel thermal management system using mist cooling for Li-ion batteries. The proposed thermal management system uses distilled water mist generated from the ultrasonic mist generator to provide cooling for the battery. The performance of the mist cooling system is compared with the conventional dry air cooling system through experiments conducted using lab prototype as well as numerical simulations of the battery module. The performance of the cooling system is assessed in terms of the average surface temperature of the battery and variation of the temperature within a battery module. It can be concluded that mist cooling system provides an excellent cooling performance to maintain the batteries temperature within optimum operating temperature range and is capable to minimize the variation of temperature across the battery module. Through the introduction of a small portion of mist into the dry air stream, the heat transfer performance of the cooling fluid is able to enhance the poor convection performance of the dry air, which then improves the overall heat transfer performance in the downstream. Furthermore, 5 gs $^{-1}$ of bulk inlet mass flow rate with $3 \%$ mist loading fractions is found to be sufficient to maintain the maximum surface temperature of the battery below $40{ }^{\circ} \mathrm{C}$ and the variation of the battery temperature is less than $5{ }^{\circ} \mathrm{C}$ for $3 \mathrm{C}$-rate of charging. The mist droplet is evaporated by absorbing heat from the battery surface to provide a cooling

effect. It is also found out that loading fraction of the misting fluid is a key parameter that affects the thermal performance of the cooling system. The present work indicates that 
by replacing the conventional forced air cooling system with mist cooling system, an improvement in the thermal performance up to $45 \%$ can be achieved. Besides, the power consumption of the mist generator is about $4.8 \mathrm{~W}$, while air cooling system consumed more power to achieve higher performance. Under aggressive US06 driving cycle, mist cooling is able to suppress the surface temperature of the battery below $40{ }^{\circ} \mathrm{C}$. Final surface temperature of the battery is about $36.5^{\circ} \mathrm{C}$. The present work concludes that mist cooling system can provide an alternative thermal management solution for Li-ion battery equipped with liquid cooling system. While the liquid cooling method requires expensive equipment such as cold plate, pump and heat exchanger, this will increase the overall weight of the EV and consequently reduce the total driving distance. Apart from that, condenser can be installed on the battery pack to collect the water droplets for recycle. In the future study, the effect of different cooling fluids and droplet sizes will be investigated for the mist cooling system.

\section{Acknowledgements}

This work was supported by Science fund Grant No. 03-02-11-SF0216 from Ministry of Science, Technology and Innovation, Malaysia. 


\section{References:}

1. Saw LH, Ye Y, Yew MC, Chong WT, Yew MK, Ng TC. Computational fluid dynamics simulation on open cell aluminium foams for Li-ion battery cooling system. Appl Ener 2017;204;298-302.

2. Cicconi P, Landi D, Germani M. Thermal analysis and simulation of Li-ion battery pack for a lightweight commercial EV. Appl Ener 2017;192:159-177.

3. Pesaran AA. Battery thermal models for hybrid vehicle simulations. J Pow Sour 2002;110:377-382.

4. Sarasketa-Zabala E, Martinez-Laserma E, Berecibar M, Gandiaga I, RodriguezMartinez LM, Villarreal I. Realistic lifetime prediction approach for Li-ion batteries. Appl Ener 2016;162:839-852.

5. Petit M, Prada E, Sauvant-Moynot V. Development of an empirical aging model for Li-ion batteries and application to assess the impact of vehicle-to-grid strategies on battery lifetime. Appl Energ 2016;172:398-407.

6. Coman PT, Darcy EC, Veje CT, White RE. Numerical analysis of heat propagation in a battery pack using a novel technology for triggering thermal runaway. Appl Energ 2017;203:189-200.

7. Kuper Ch, Hoh M, Houchin-Miller G, Fuhr J. Thermal management of hybrid vehicle battery systems, Proceeding of EVS24 International Battery, Hybrid and Fuel Cell Electric Vehicle Symposium. Stavanger, Norway, 2009.

8. Rao Z, Wang S. A review of power battery thermal energy management. Renew Sust Energ Rev 2011;15:4554-4571.

9. Saw LH, Ye Y, Tay AAO, Chong WT, Kuan SH, Yew MC. Computational fluid dynamic and thermal analysis of Lithium-ion battery pack with air cooling. Appl Energ 2016;177:783-792.

10. Jarrett A, Kim IY. Influence of operating conditions on the optimum design of electric vehicle battery cooling plates. J Pow Sour 2014;245:644-655.

11. Somasundaram K, Birgersson E, Mujumdar AS. Thermal-electrochemical model for passive thermal management of a spiral-wound lithium-ion battery. J Pow Sour 2012;203:84-96.

12. Rao Z, Wang Q, Huang C. Investigation of the thermal performance of phase change material/mini-channel coupled battery thermal management system. Appl Energ 2016;164:659-669. 
13. Ling Z, Wang F, Fang X, Gao X, zhang Z. A hybrid thermal management system for lithium ion batteries combining phase change materials with forcedair cooling. Appl Energ 2015;148:403-409.

14. Mahamud R, Park CW. Reciprocating air flow for Li-ion battery thermal management to improve temperature uniformity. J Pow Sour 2011;196:56855696.

15. Mi C, Li B, Buck D, Ota N. Advanced electro-thermal modelling of Lithium-ion battery system for hybrid electric vehicle applications. Vehicle power and Propulsion Conference. Arlington, USA. 2007.

16. Vita AD, Maheshwari A, Destro M, Santarelli M, Carello M. Transient thermal analysis of a lithium-ion battery pack comparing different cooling solutions for automotive applications. Appl Energ 2017;206:101-112.

17. Basu S, Hariharan KS, Kolake SM, Song T, Sohn DK, Yeo T. Coupled electrochemical thermal modelling of a novel Li-ion battery pack thermal management system. Appl Energ 2016;181:1-13.

18. Ling Z, Wang F, Fang, X, Gao X, Zhang Z. A hybrid thermal management system for lithium ion batteries combining phase change materials with forcedair cooling. Appl Energ 2015;403-409.

19. Zhao R, Gu J, Liu J. An experimental study of heat pipe thermal management system with wet cooling method for lithium ion batteries. J Pow Sour 2015;273:1089-1097.

20. Tran TH, Harmand S, Desmet B, Filangi S. Experimental investigation on the feasibility of heat pipe cooling for HEV/EV lithium-in battery. Appl Therm Eng 2014;63:551-558.

21. Howes JC, Levett DB, Wilson ST, Marsala J, Saums DL. Cooling of an IGBT drive system with vaporizable dielectric fluid (VDF). $24^{\text {th }}$ SEMI-THERM. (2008); 9-15.

22. Jiang $Y$, Zheng Q, Dong $\mathrm{P}$, Yao J, Zhang H, Gao J. Conjugate heat transfer analysis of leading edge and downstream mist-air film cooling on turbine vane. Int J Heat Mass Trans 2015;90:613-626.

23. Kumari N, Bahadur V, Hodes M, Salamon T, Kolodner P, Lyons A, Garimella SV. Analysis of evaporating mist flow for enhanced convective heat transfer. Int J Heat Mass Trans 2010;53:3346-3356.

24. Dhanasekaran TS, Wang T. Computational analysis of mist/air cooling in a twopass rectangular rotating channel with 45-deg angled rib turbulators. Int J Heat Mass Trans 2013;61:554-564. 
25. Jiang Y, Zheng Q, Dong P, Yao J, Zhang H, Gao J. Conjugate heat transfer analysis of leading edge and downstream mist-air film cooling on turbine vane. . Int J Heat Mass Trans 2015;90:613-626.

26. Kumari N, Bahadur V, Hodes M, Salamon T, Kolodner P, Lyons A, Garimella SV. Analysis of evaporating mist flow for enhanced convective heat transfer. Int J Heat Mass Trans 2010;53:3346-3356.

27. Saw LH, Ye Y, Tay AAO. Feasibility study of Boron Nitride coating on Lithium ion battery casing. J Appl Therm Eng 2014;73:152-159.

28. Saw LH, Somasundaram K, Ye Y, Tay AAO. Electro-thermal analysis of Lithium Iron Phosphate battery for electric vehicles. J Power Sources 2014;249:231-238.

29. Kewalramani GV, Agrawal A, Saha SK. Modeling of microchannel heat sinks for electronic cooling applications using volume averaging approach. Int J Heat Mass Trans 2017;115:395-409.

30. Ansys, ANSYS CFX-Solver modelling guide, Canonsburg: Ansys Inc; 2010.

31. Launder BE, Spalding DB. Lectures in mathematical models of turbulence. Academic Press, London, England. 1972.

32. Wang S, Li Y, Li YZ, Mao Y, Zhang Y, Guo W, Zhong M. A forced gas cooling circle packaging with liquid cooling plate for the thermal management of Li-ion batteries under space environment. Appl Therm Eng 2017;123:929-939.

33. Saw LH, Ye Y, Tay AAO. Electro-thermal analysis and integration issues of lithium ion battery for electric vehicles. Appl Energ 2014;131:97-107.

34. Samad NA, Wang B, Siegel JB, Stefanopoulou AG. Parametrization of battery electro-thermal models coupled with finite element flow models for cooling. J Dyn Sys Meas Control 2017;139:071003.

35. Kim SU, Albertus P, Cook D, Monroe CW, Christensen J. Thermoelectrochemical simulations of performance and abuse in 50-Ah automotive cells. J Pow Sour 2014;268:625-633.

36. Incropera FP, Dewitt DP, Bergman TL, Lavine AS. Fundamentals of Heat and Mass Transfer. $6^{\text {th }}$ ed. United State of America: John Wiley \& Sons; 2007.

37. Moffat RJ. Describing the uncertainties in experimental results. Exp Therm Fluid Sci 1998;1:3-17. 
Table 1. Specifications of the 38120 Lithium Iron Phosphate battery.

\begin{tabular}{lcll} 
Parameter & Value & Parameter & Value \\
\hline Nominal voltage, $\mathrm{V}$ & 3.2 & Internal resistance, $\Omega$ & 0.0034 \\
Nominal capacity, Ah & 8.0 & Reference temperature, $\mathrm{K}$ & 303.15 \\
Weight, kg & 0.335 & Cell length, $\mathrm{m}$ & 0.146 \\
Cathode material & $\mathrm{LiFePO}_{4}$ & Cell diameter, $\mathrm{m}$ & 0.038 \\
Specific heat capacity, $\mathrm{Jkg}^{-1} \mathrm{~K}^{-1}$ & 998 & Anode material & Graphite \\
$\begin{array}{l}\text { Thermal conductivity in radial } \\
\text { direction, } \mathrm{Wm}^{-1} \mathrm{~K}^{-1}[9]\end{array}$ & 0.2 & $\begin{array}{l}\text { Thermal conductivity in } \\
\text { axial direction, } \mathrm{Wm}^{-1} \mathrm{~K}^{-1}[9]\end{array}$ & 37.6 \\
\hline
\end{tabular}


Table 2. Boundaries details and settings of the test rig and battery module in ANSYS CFX.

\begin{tabular}{|c|c|c|}
\hline \multicolumn{3}{|c|}{ Test rig } \\
\hline Boundary Name & Boundary details & \\
\hline \multirow[t]{2}{*}{ Inlet } & Temperature & $30^{\circ} \mathrm{C}$ \\
\hline & Turbulence Intensity & $5 \%$ \\
\hline Outlet & Pressure outlet & $0 \mathrm{~Pa}$ \\
\hline \multirow[t]{2}{*}{ Fluid domain } & Non-contact wall & Non slip \\
\hline & Non-contact wall heat Transfer & Adiabatic \\
\hline \multirow[t]{2}{*}{ Copper rod } & Initial temperature & $30^{\circ} \mathrm{C}$ \\
\hline & Non-contact wall heat transfer & Adiabatic \\
\hline \multirow[t]{2}{*}{ Casing } & Initial temperature & $30^{\circ} \mathrm{C}$ \\
\hline & Non-contact wall heat Transfer & Adiabatic \\
\hline \multicolumn{3}{|c|}{ Battery module } \\
\hline Boundary Name & Boundary details & \\
\hline \multirow[t]{2}{*}{ Inlet } & Temperature & $30^{\circ} \mathrm{C}$ \\
\hline & Turbulence Intensity & $5 \%$ \\
\hline Outlet & Pressure outlet & $0 \mathrm{~Pa}$ \\
\hline \multirow[t]{2}{*}{ Fluid domain } & Non-contact wall & Non slip \\
\hline & Non-contact wall heat Transfer & Adiabatic \\
\hline \multirow[t]{2}{*}{ Battery } & Initial temperature & $30^{\circ} \mathrm{C}$ \\
\hline & Non-contact wall heat transfer & Adiabatic \\
\hline \multirow[t]{2}{*}{ Casing } & Initial temperature & $30{ }^{\circ} \mathrm{C}$ \\
\hline & Non-contact wall heat Transfer & Adiabatic \\
\hline
\end{tabular}


Table 3. Results of grid independent test.

\begin{tabular}{|c|c|c|c|c|c|}
\hline Mesh No & Mesh-1 & Mesh-2 & $\begin{array}{c}\% \\
\text { deviation }\end{array}$ & Mesh-3 & $\begin{array}{c}\% \\
\text { deviation }\end{array}$ \\
\hline \multicolumn{6}{|l|}{ Test rig } \\
\hline Number of element & $3,462,732$ & $5,497,946$ & & $7,379,809$ & \\
\hline Average temperature, ${ }^{\circ} \mathrm{C}$ & 48.96 & 48.71 & $0.51 \%$ & 48.31 & $0.82 \%$ \\
\hline Pressure drop, $\mathrm{Pa}$ & 1.250 & 1.198 & $2.44 \%$ & 1.234 & $3.01 \%$ \\
\hline \multicolumn{6}{|l|}{ Battery module } \\
\hline Number of element & $1,281,928$ & $2,515,954$ & & $5,325,389$ & \\
\hline Average temperature, ${ }^{\circ} \mathrm{C}$ & 59.42 & 59.02 & $0.67 \%$ & 58.95 & $0.12 \%$ \\
\hline Pressure drop, $\mathrm{Pa}$ & 1.514 & 1.516 & $0.13 \%$ & 1.524 & $0.53 \%$ \\
\hline
\end{tabular}


Table 4. Nusselt number correlation for the single cell and battery module under forced air and mist cooling.

\begin{tabular}{|c|c|c|c|c|}
\hline & Coefficient, $A$ & Power of $R e, m$ & Power of $\operatorname{Pr}, n$ & Eq. \\
\hline \multicolumn{5}{|c|}{ Single cell test rig } \\
\hline Forced air cooling & 0.150 & 0.683 & 0.33 & 31 \\
\hline Mist cooling & 0.913 & 0.501 & 0.33 & 32 \\
\hline \multicolumn{5}{|c|}{ Battery module } \\
\hline Forced air cooling & 0.204 & 0.669 & 0.33 & 33 \\
\hline $1 \%$ of mist loading fraction & 13.707 & 0.303 & 0.33 & 35 \\
\hline $3 \%$ of mist loading fraction & 129.046 & 0.146 & 0.33 & 36 \\
\hline $5 \%$ of mist loading fraction & 302.528 & 0.0996 & 0.33 & 37 \\
\hline
\end{tabular}


Fig. 1. CAD model of the cylindrical battery module.

Fig. 2. Schematic of the dummy cell test rig.

Fig. 3. (a) Boundary conditions of the test rig. (b) Boundary conditions of the battery module.

Fig. 4. Heat generation of the 38120 cell during various C-rates of charging.

Fig. 5. Heat generation of the 38120 cell during various C-rates of discharging.

Fig. 6. Battery surface temperature under various C-rates of charging in the ARC.

Fig. 7. Battery surface temperature under various C-rates of discharging in the ARC.

Fig. 8. Evolution of dummy battery surface temperature under different mass flow rates of dry air.

Fig. 9. Temperature contour plot of forced convection with dry air at $11.2 \mathrm{gs}^{-1}$.

Fig. 10. Friction factor versus Reynolds number for the dummy cell test rig under forced air cooling.

Fig. 11. Evolution of dummy battery surface temperature under different mass flow rates of mist cooling.

Fig. 12. Temperature contour plot of forced convection with mist cooling at 7.5 gs $^{-1}$.

Fig. 13. Friction factor versus Reynolds number for the dummy cell test rig under mist cooling.

Fig. 14. Average surface temperature of the batteries in the module with different mass flow rates of cooling air.

Fig. 15. Variation of temperature in the battery module with different mass flow rates of cooling air.

Fig. 16. Temperature contour plot of the battery module under dry air cooling.

Fig. 17. Ideal fan power consumption with different mass flow rates of cooling air.

Fig. 18. Development of friction factor with different mass flow rates of cooling air.

Fig. 19. Average surface temperature of the batteries in the module with different inlet mist loading fractions.

Fig. 20. Variation of surface temperature in the battery module with different inlet mist loading fractions. 
Fig. 21. Temperature contour plot of the battery module under $5 \mathrm{gs}^{-1}$ mass flow rate with $3 \%$ of inlet mist loading fraction.

Fig. 22. Development of battery internal temperature under $5 \mathrm{gs}^{-1}$ mass flow rate with $3 \%$ of inlet mist loading fraction.

Fig. 23. Development of friction factor with different inlet mist loading fractions.

Fig. 24. Predicted temperature rise of the battery surface temperature for 1,3 and 5 Crates of charging.

Fig. 25. Predicted temperature rise of the battery surface temperature for 1,2 and 3 Crates of discharging.

Fig. 26. Predicted temperature rise of the battery module under US06 driving cycle. 


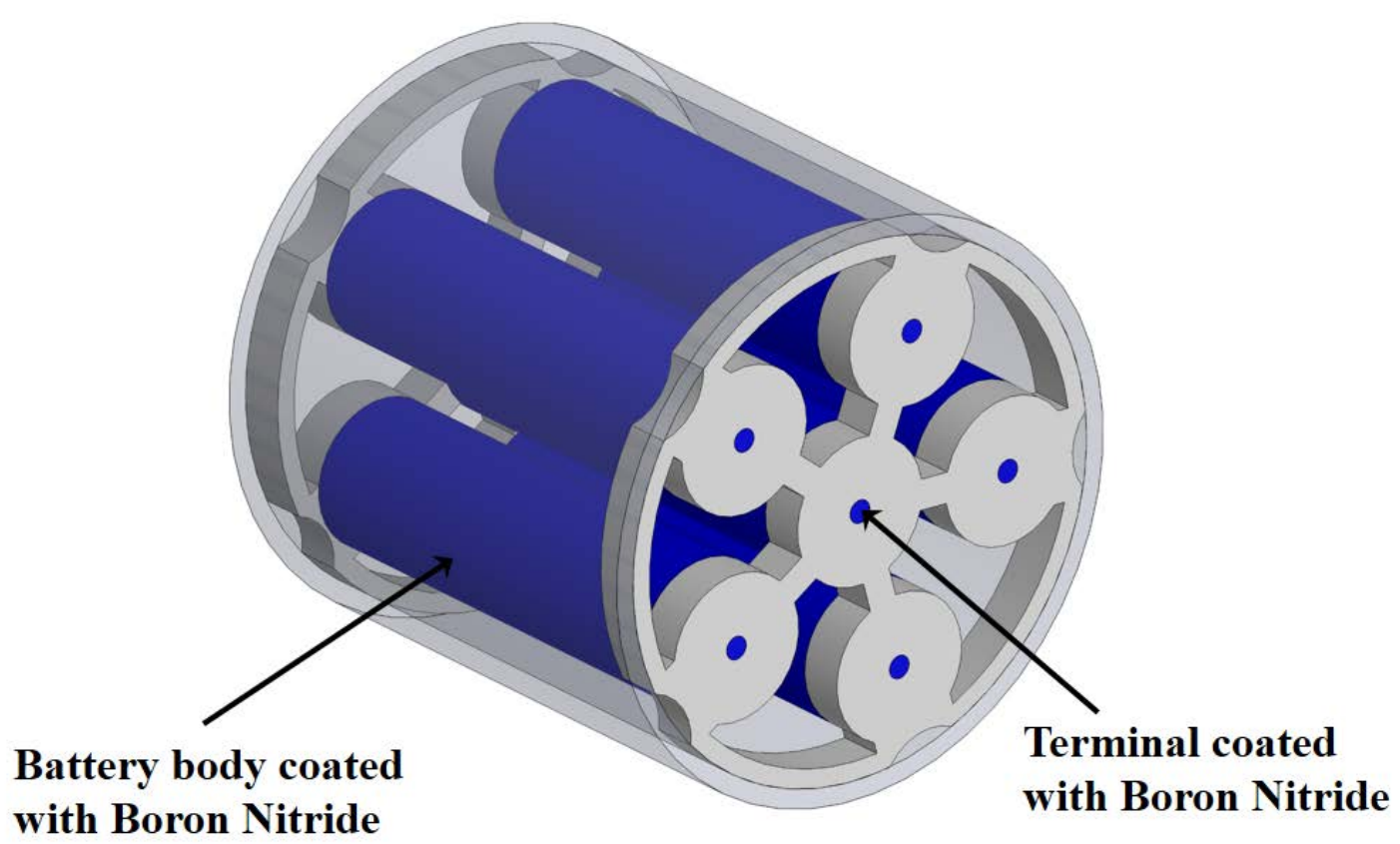




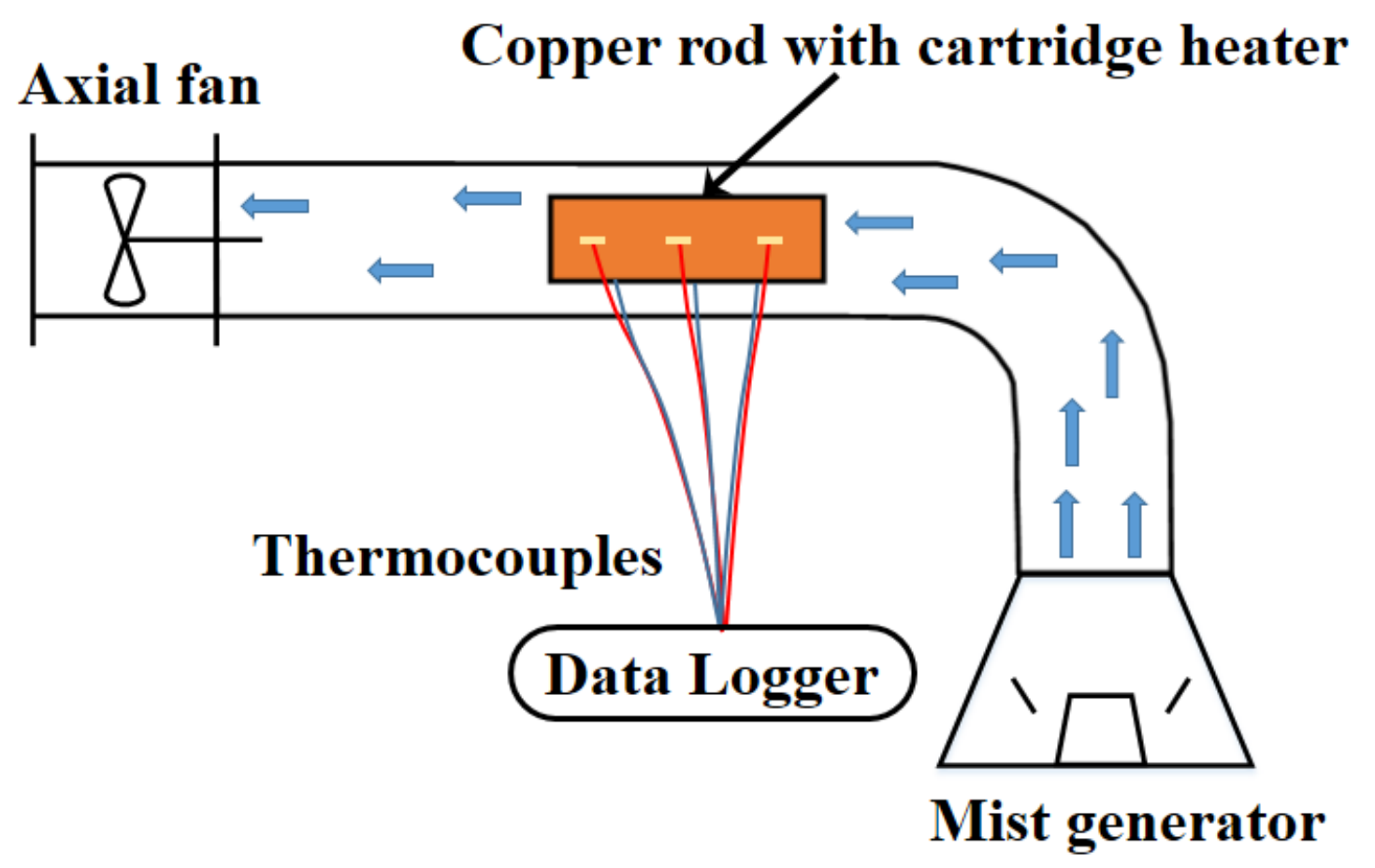


(a) Cartridge heater

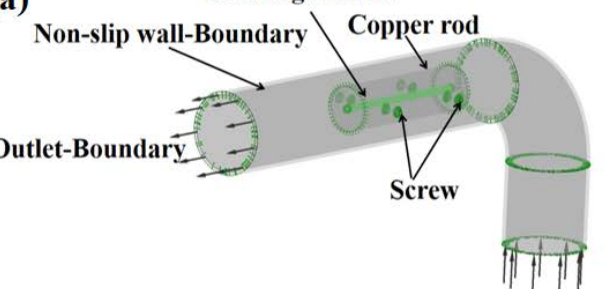

(b)

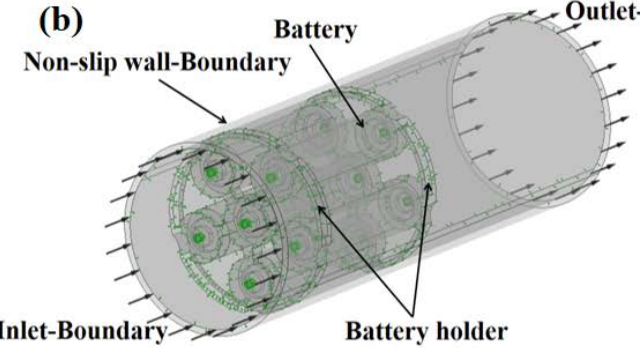




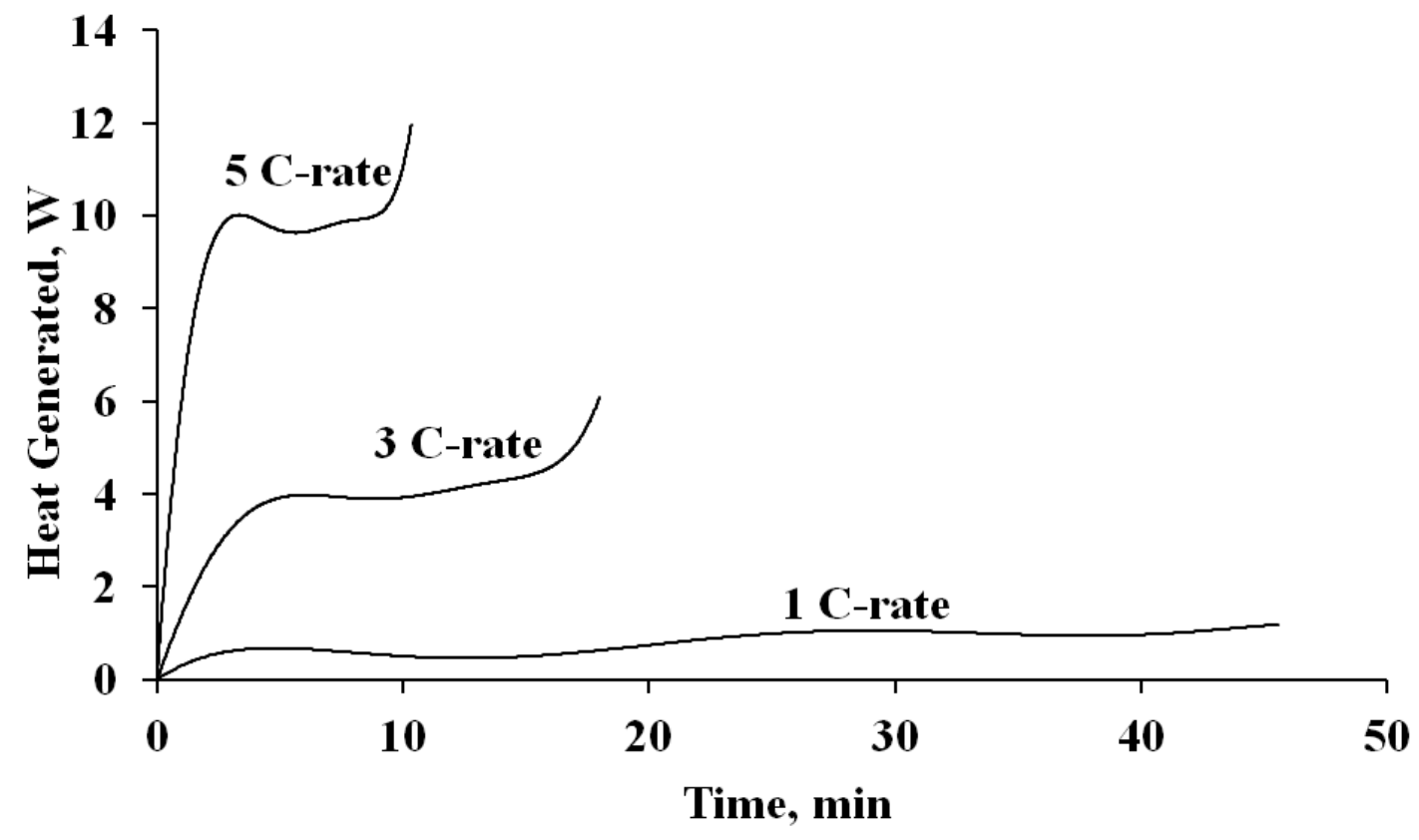




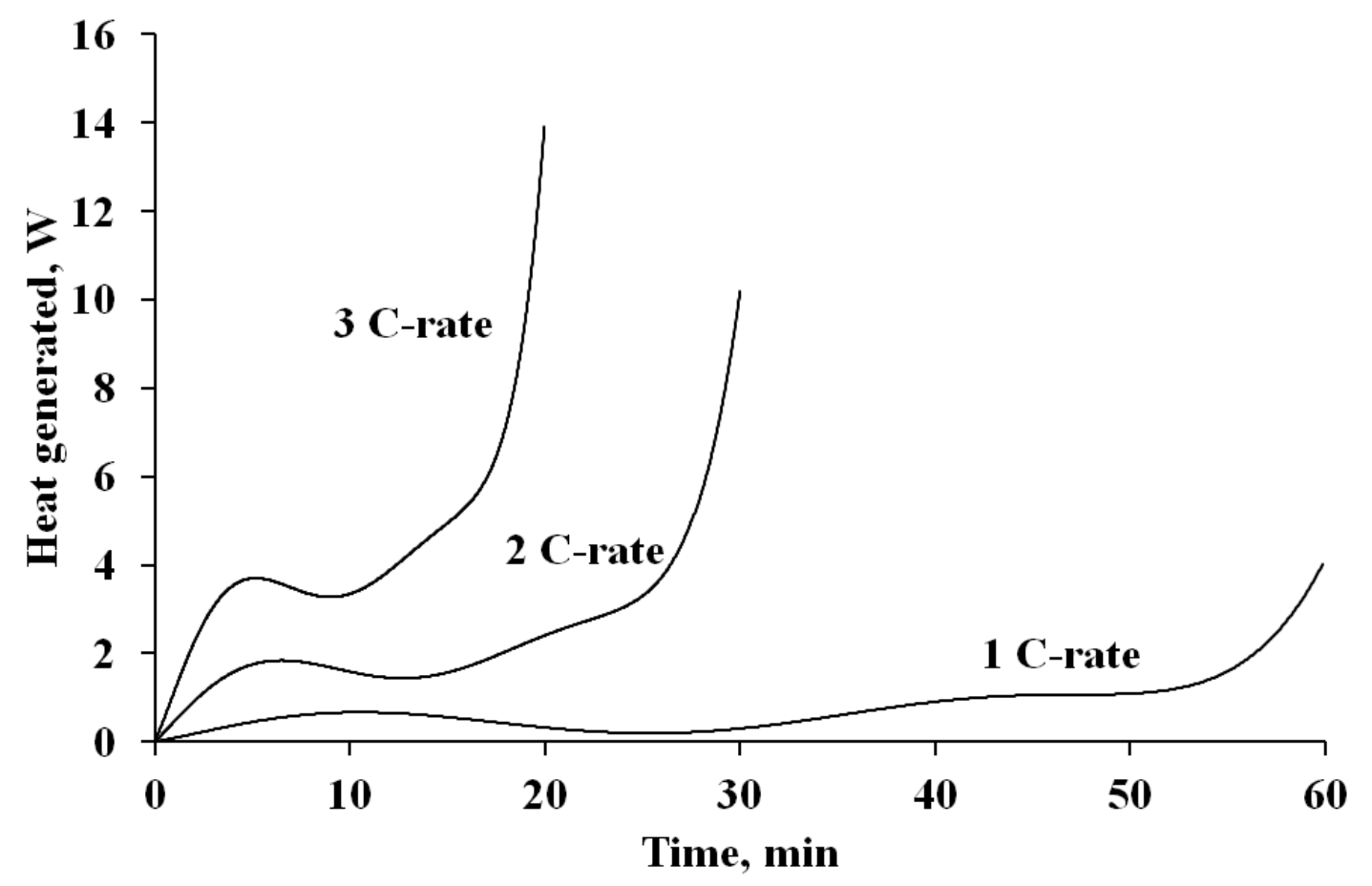




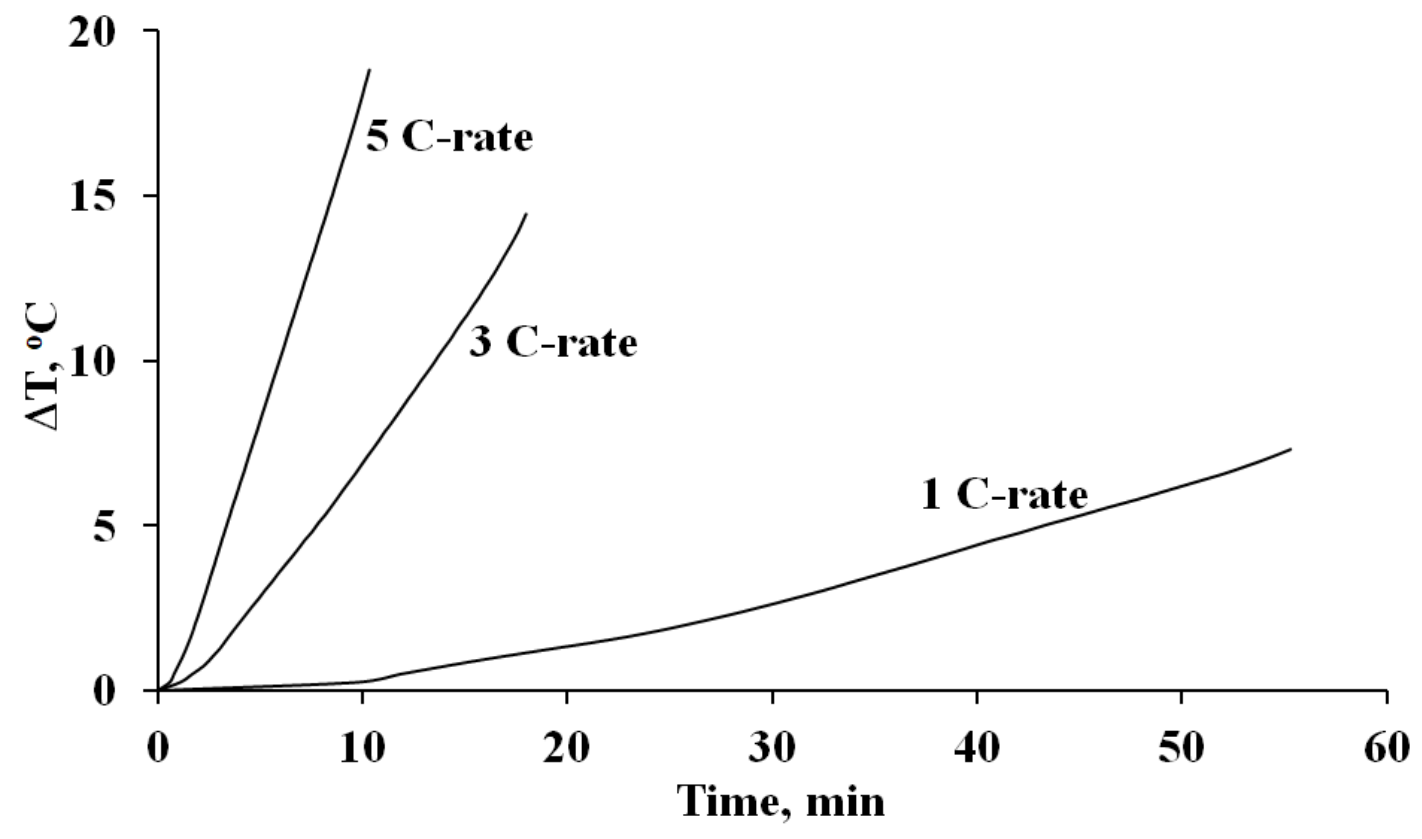




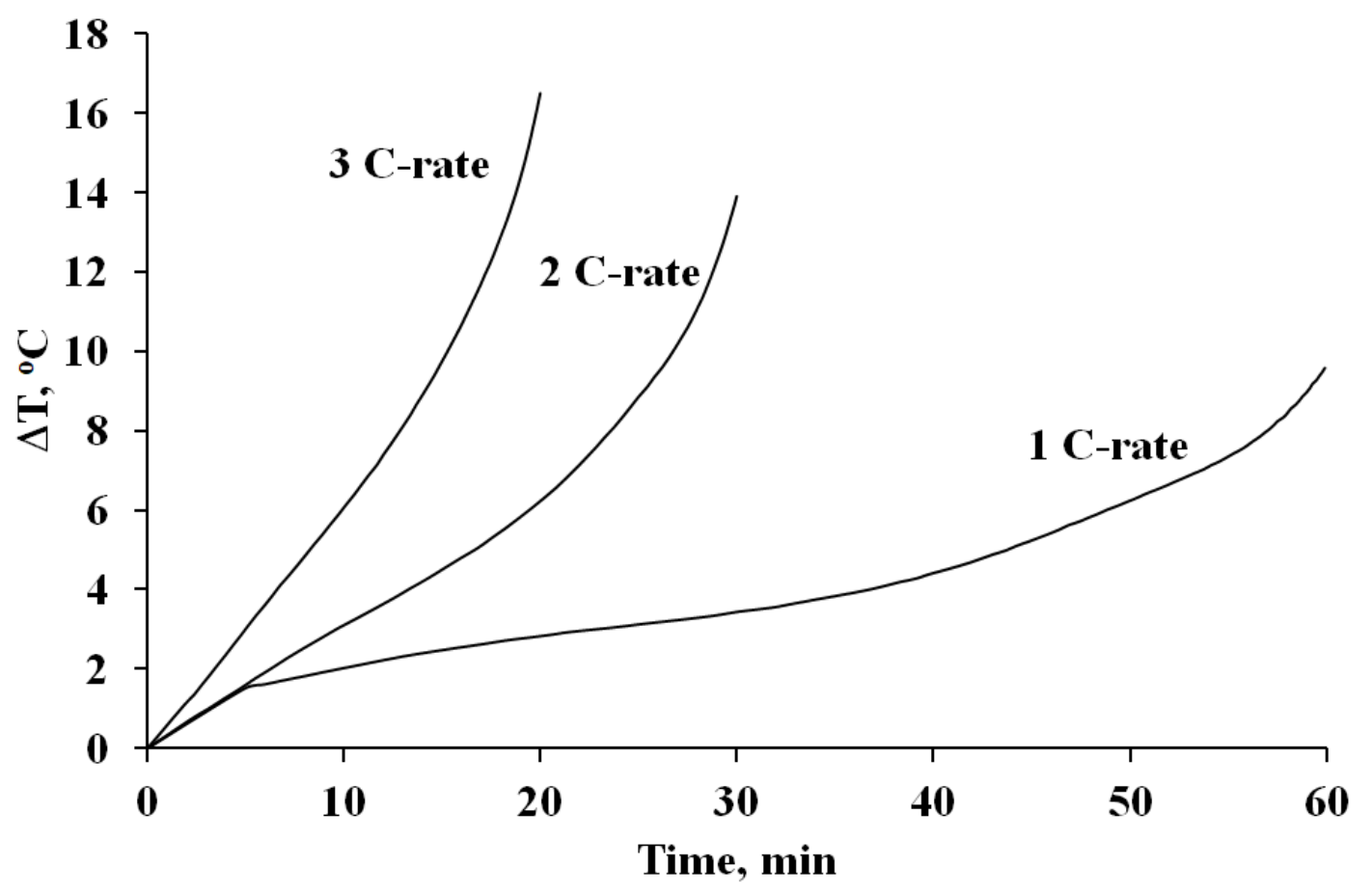




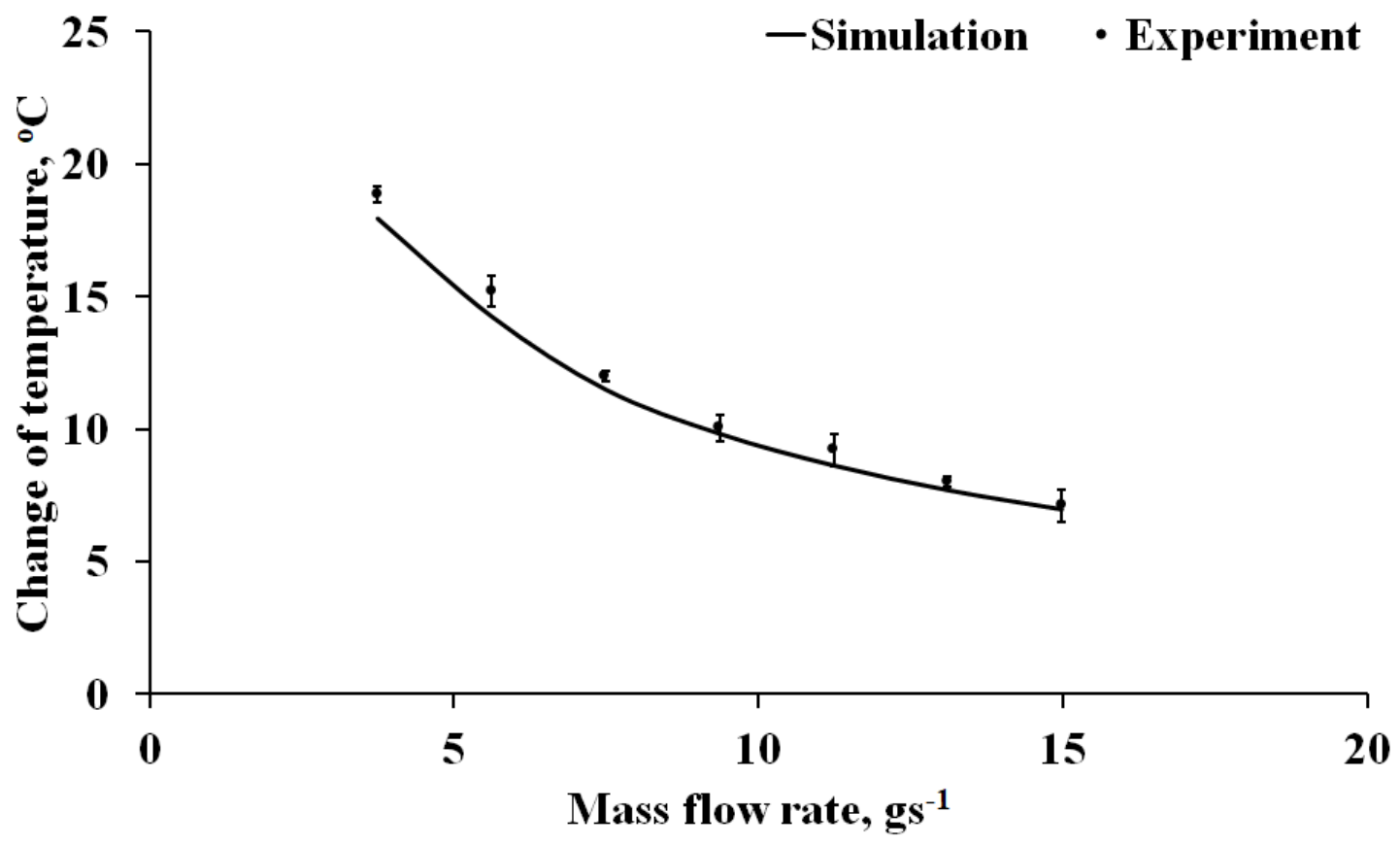




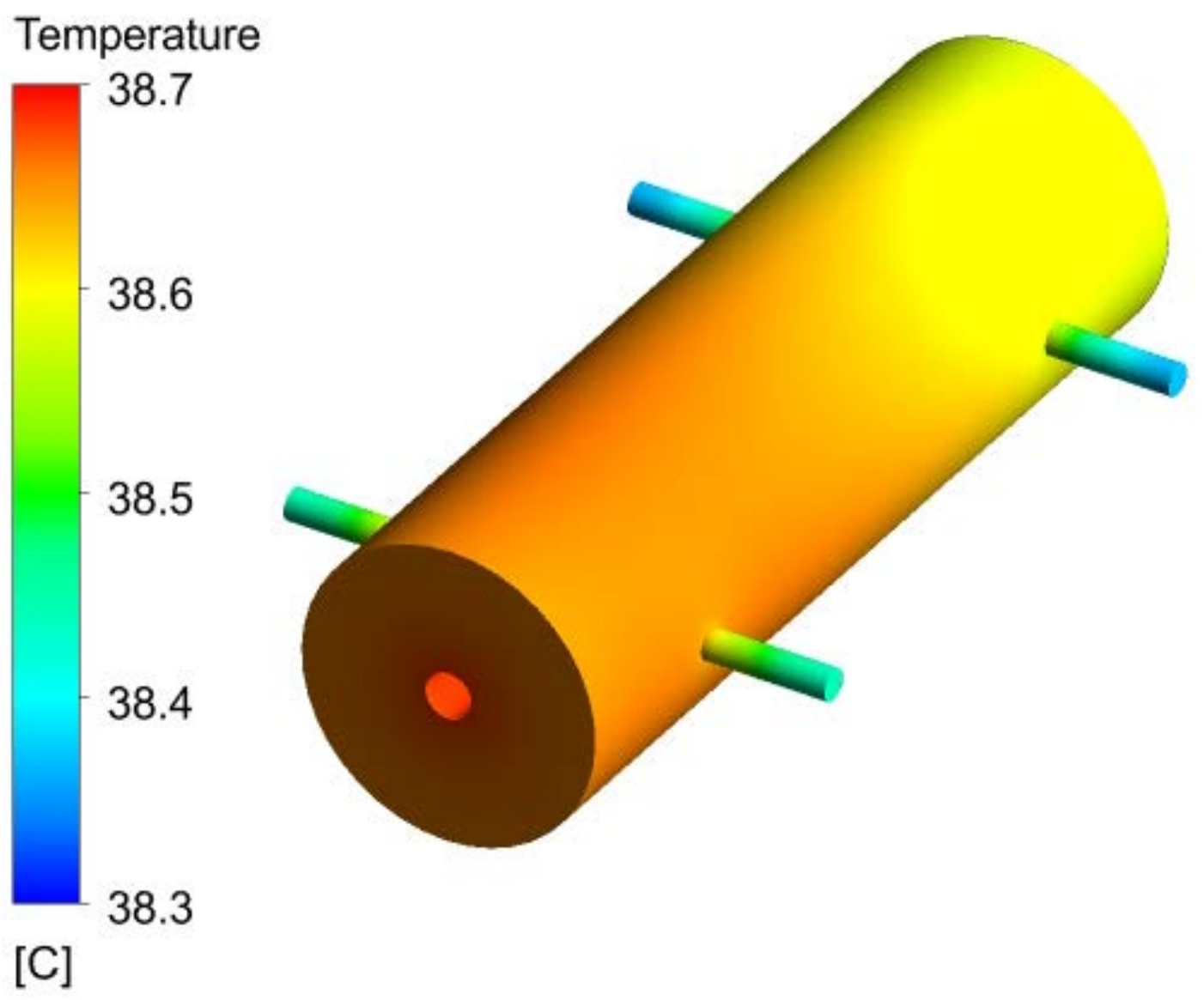




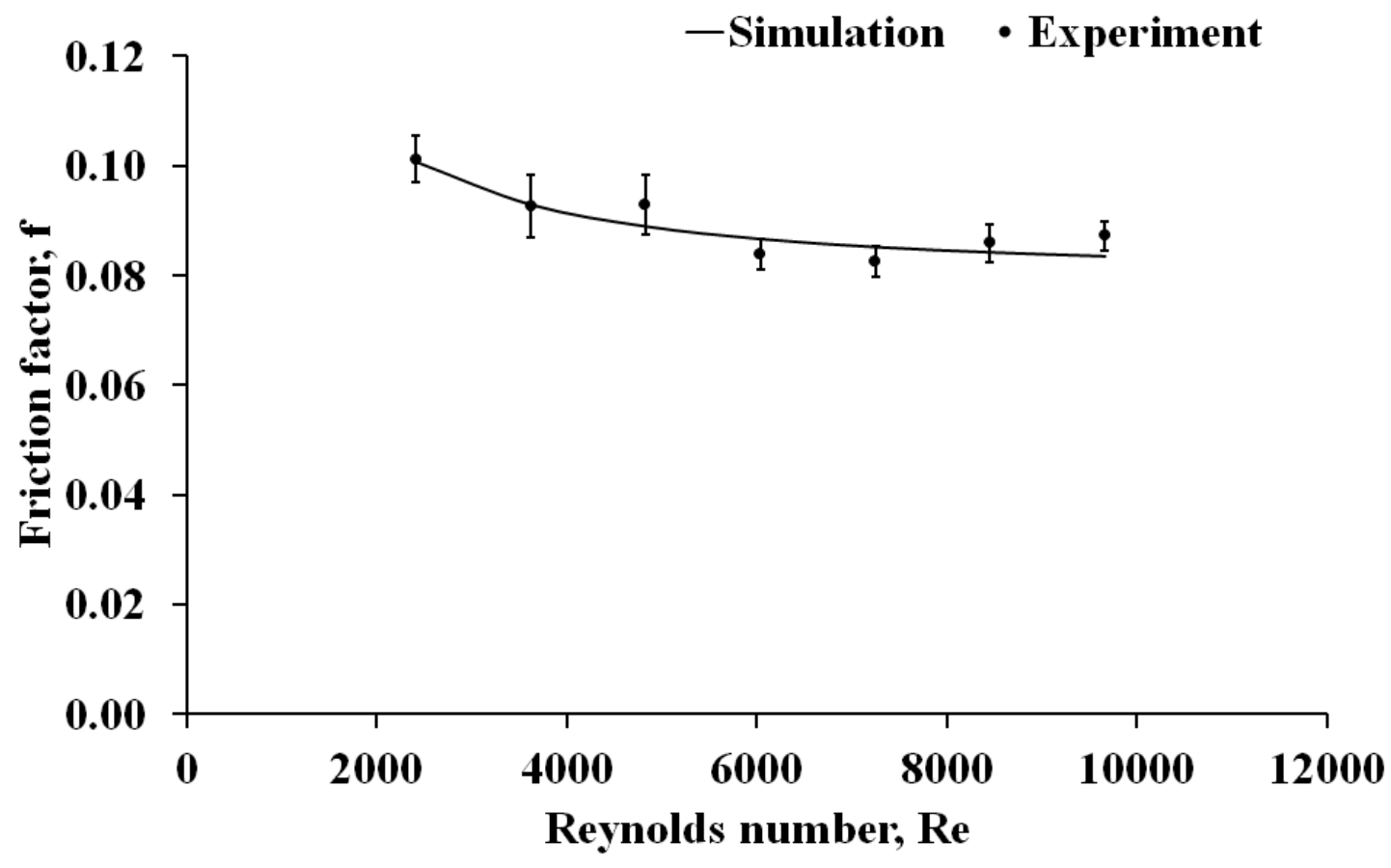




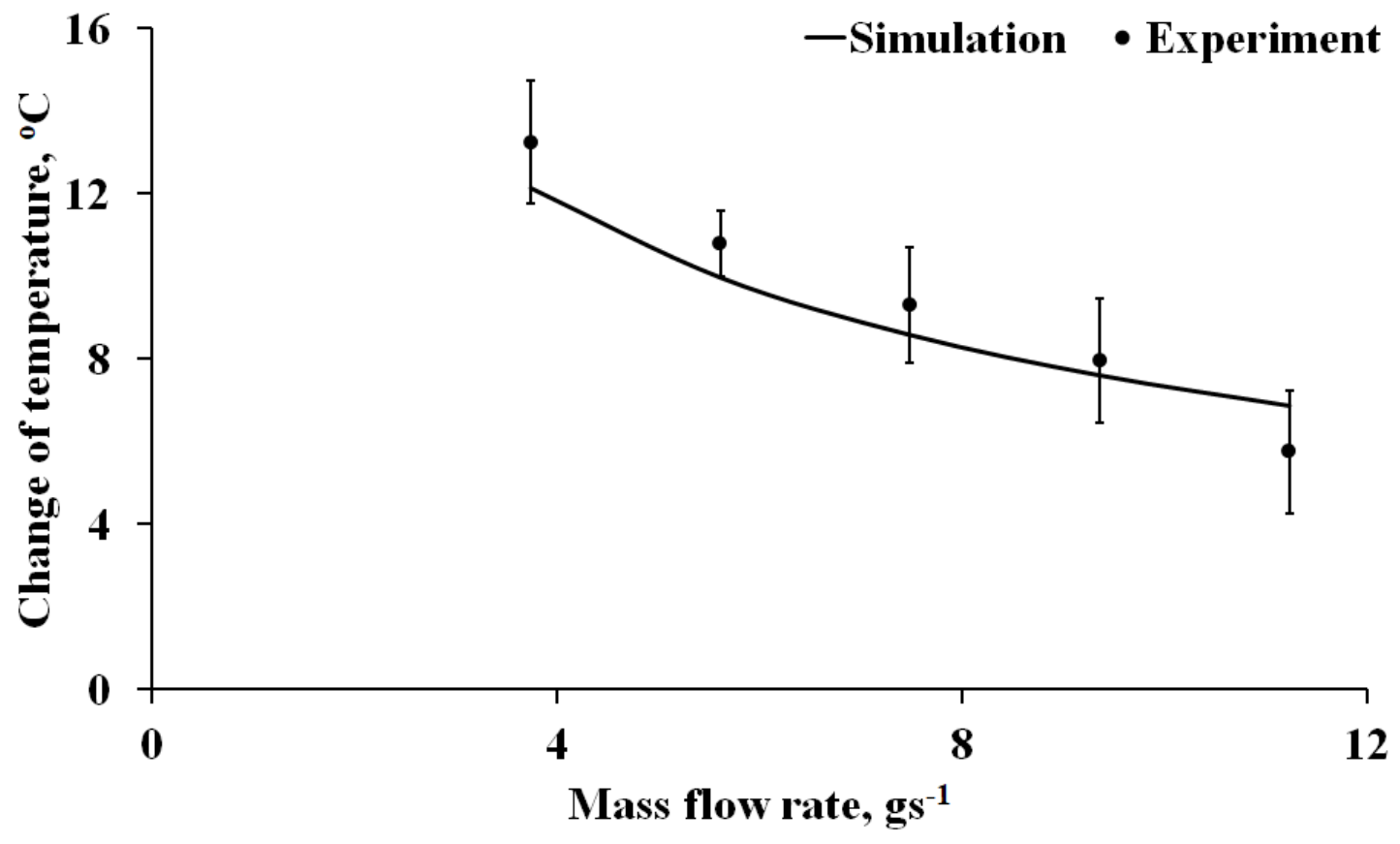




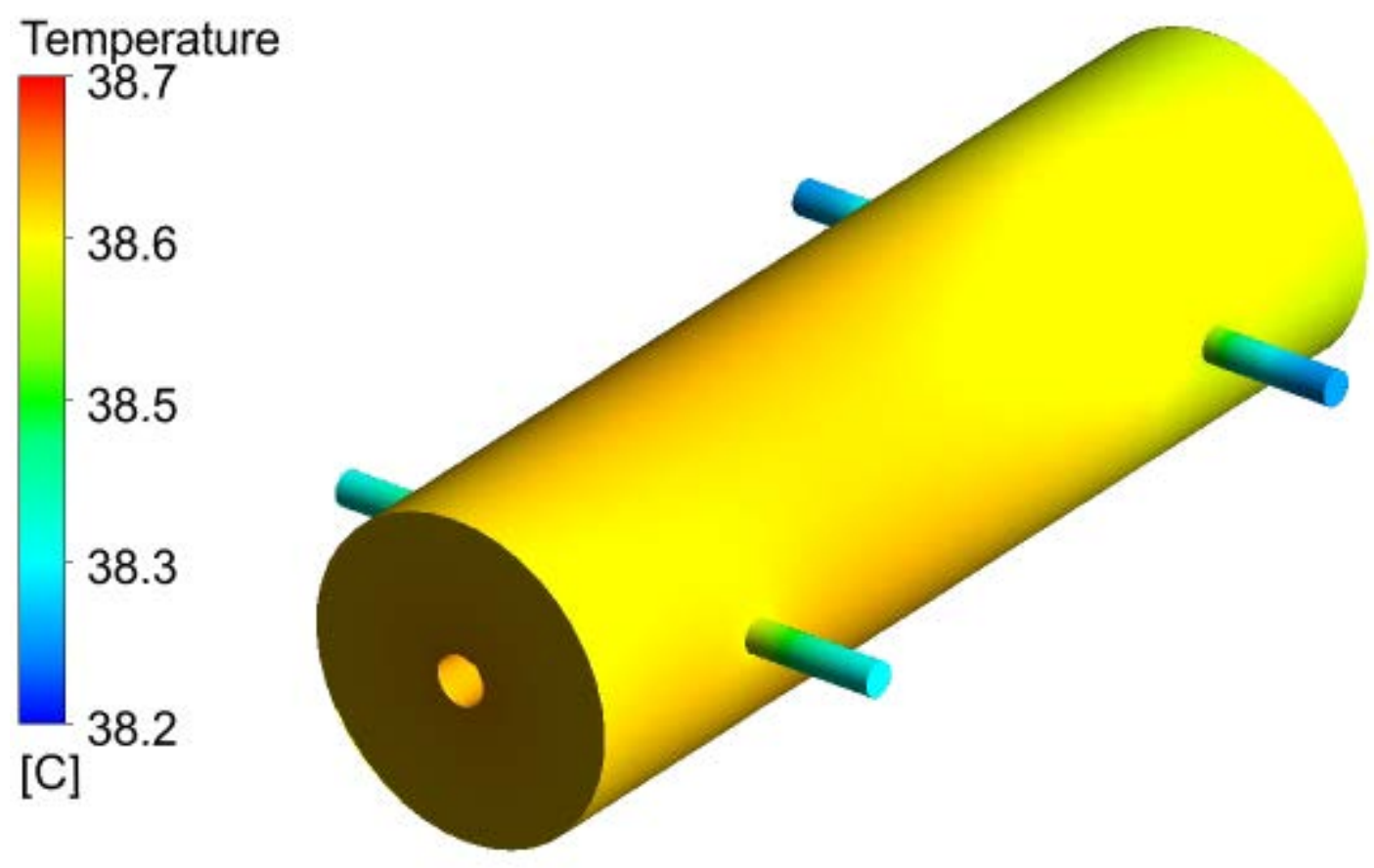




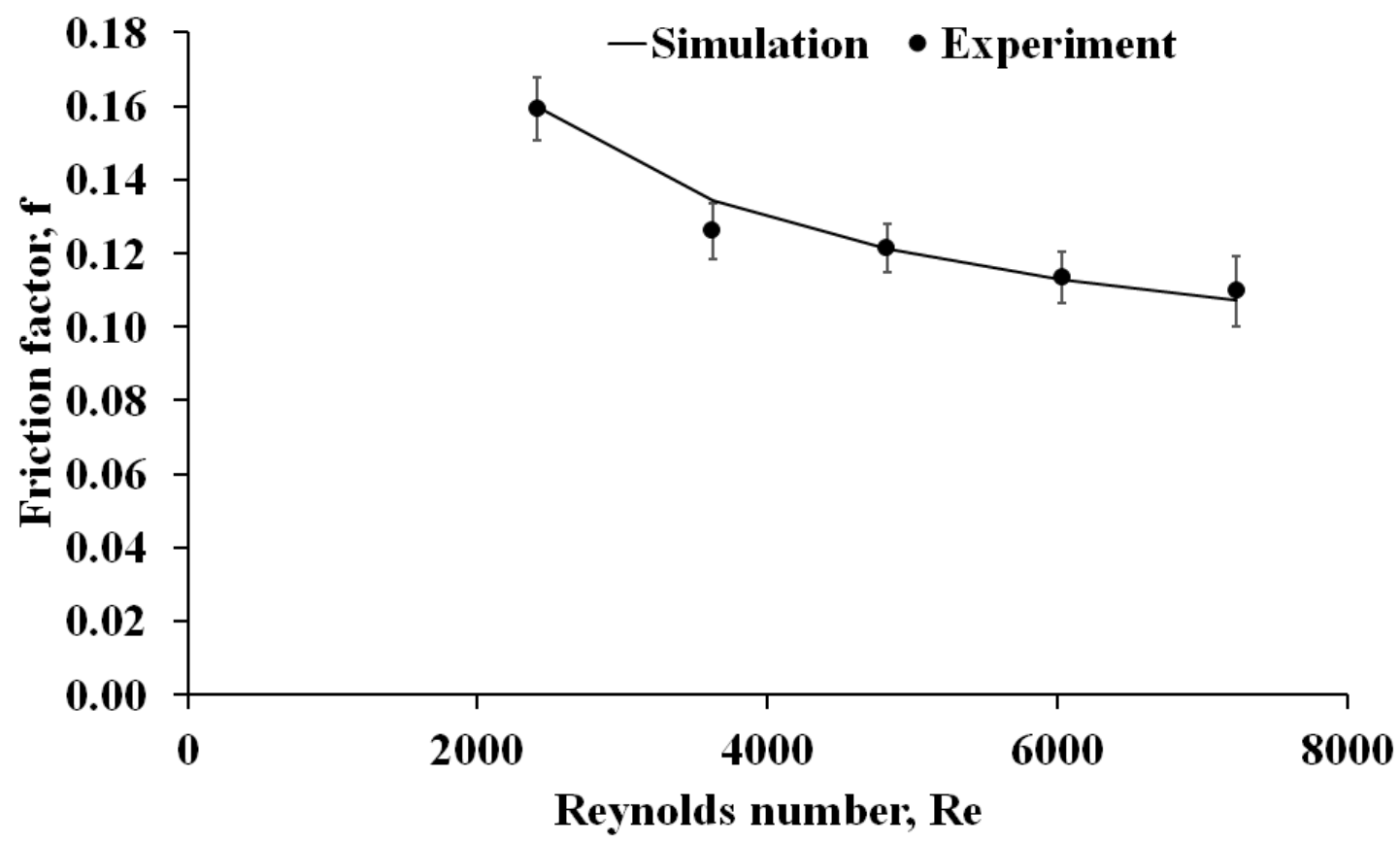




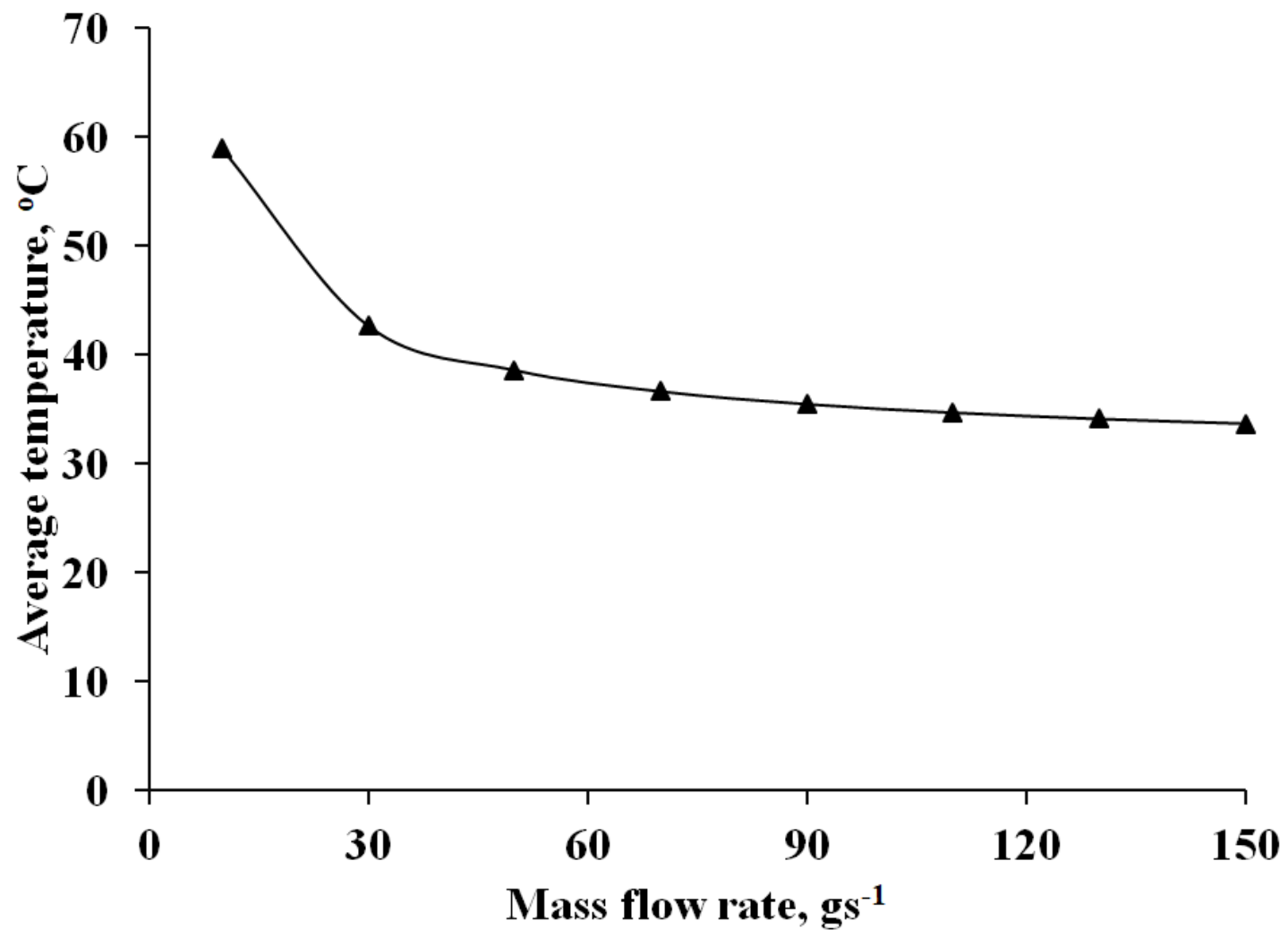




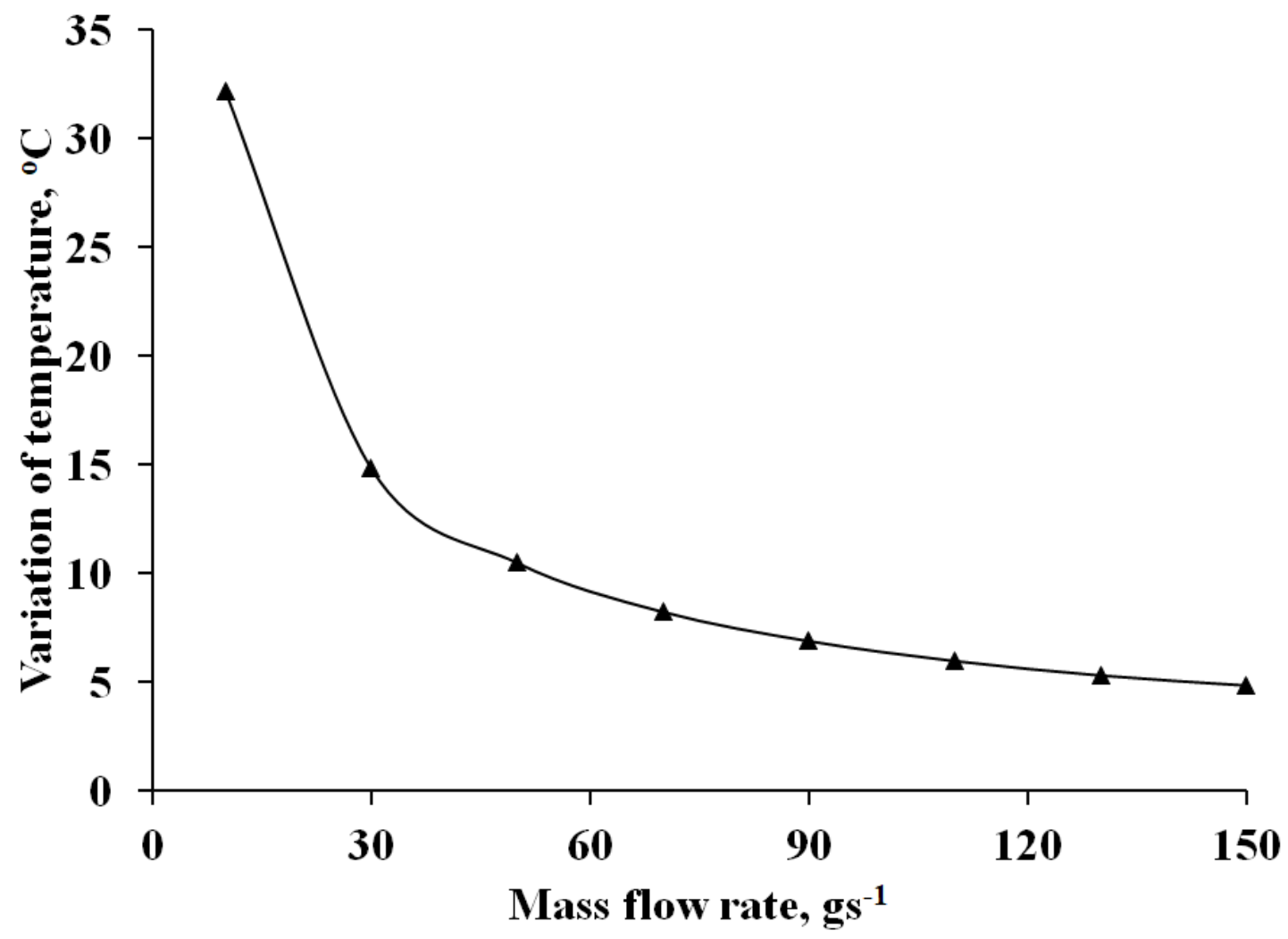


Temperature

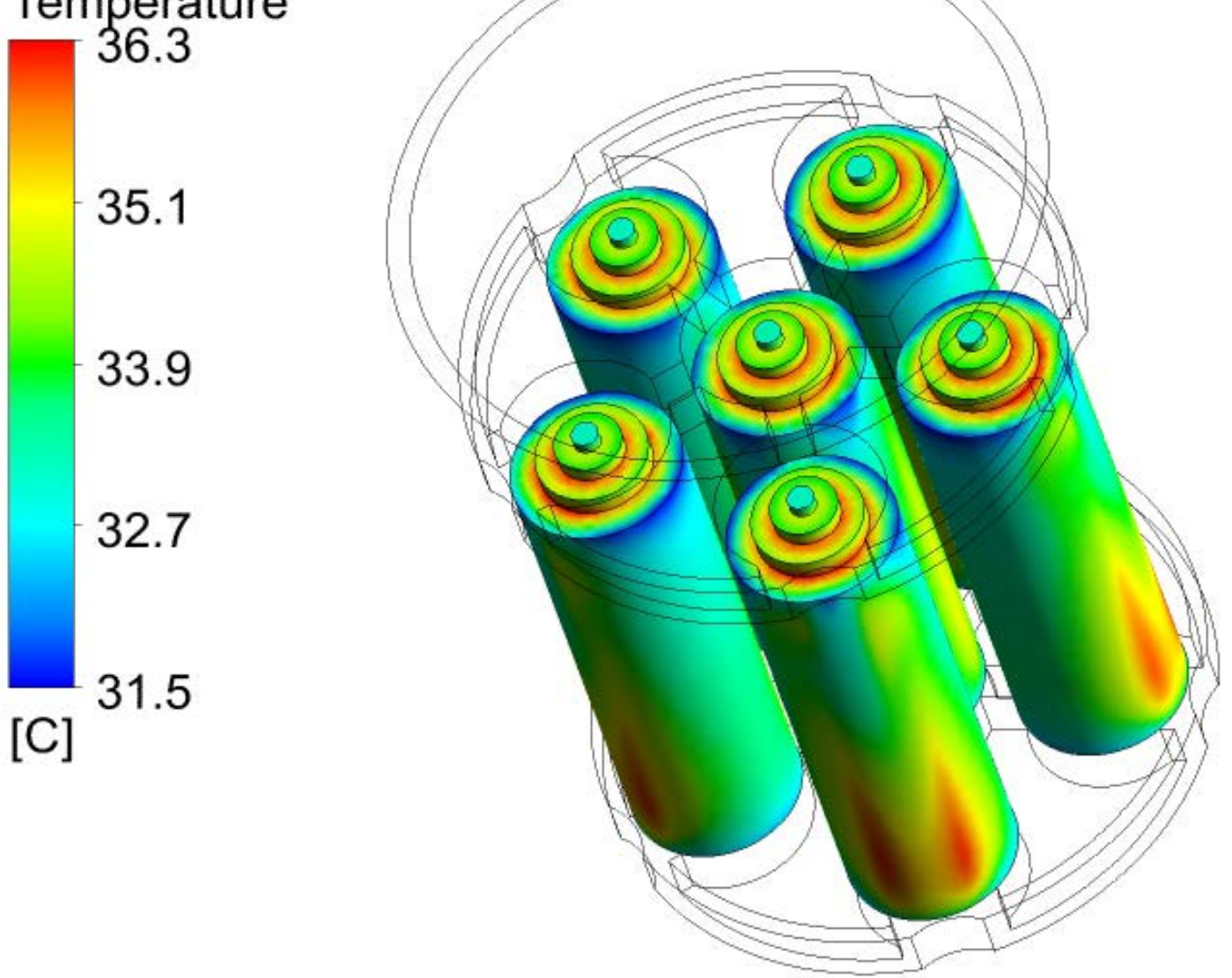




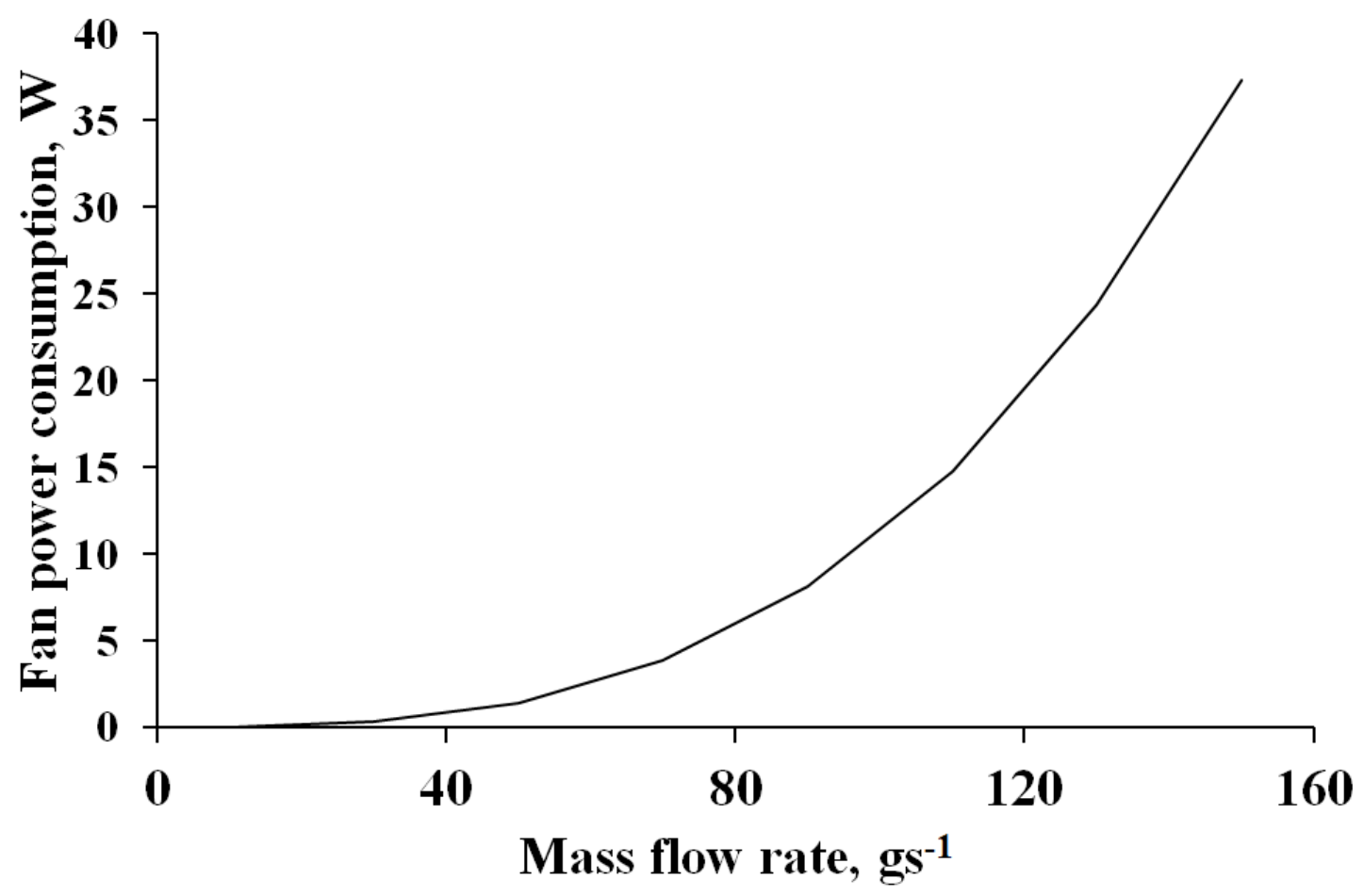




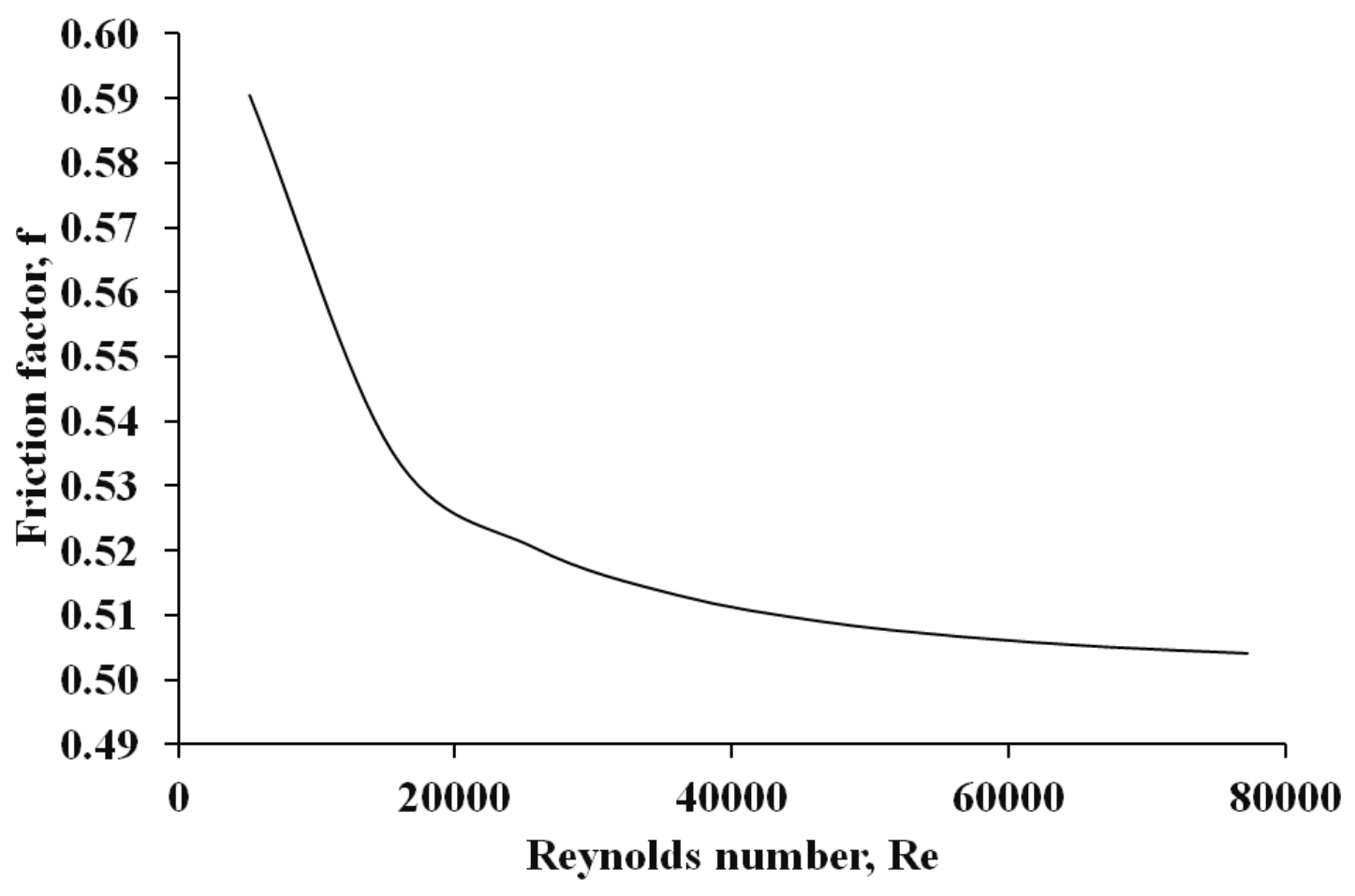




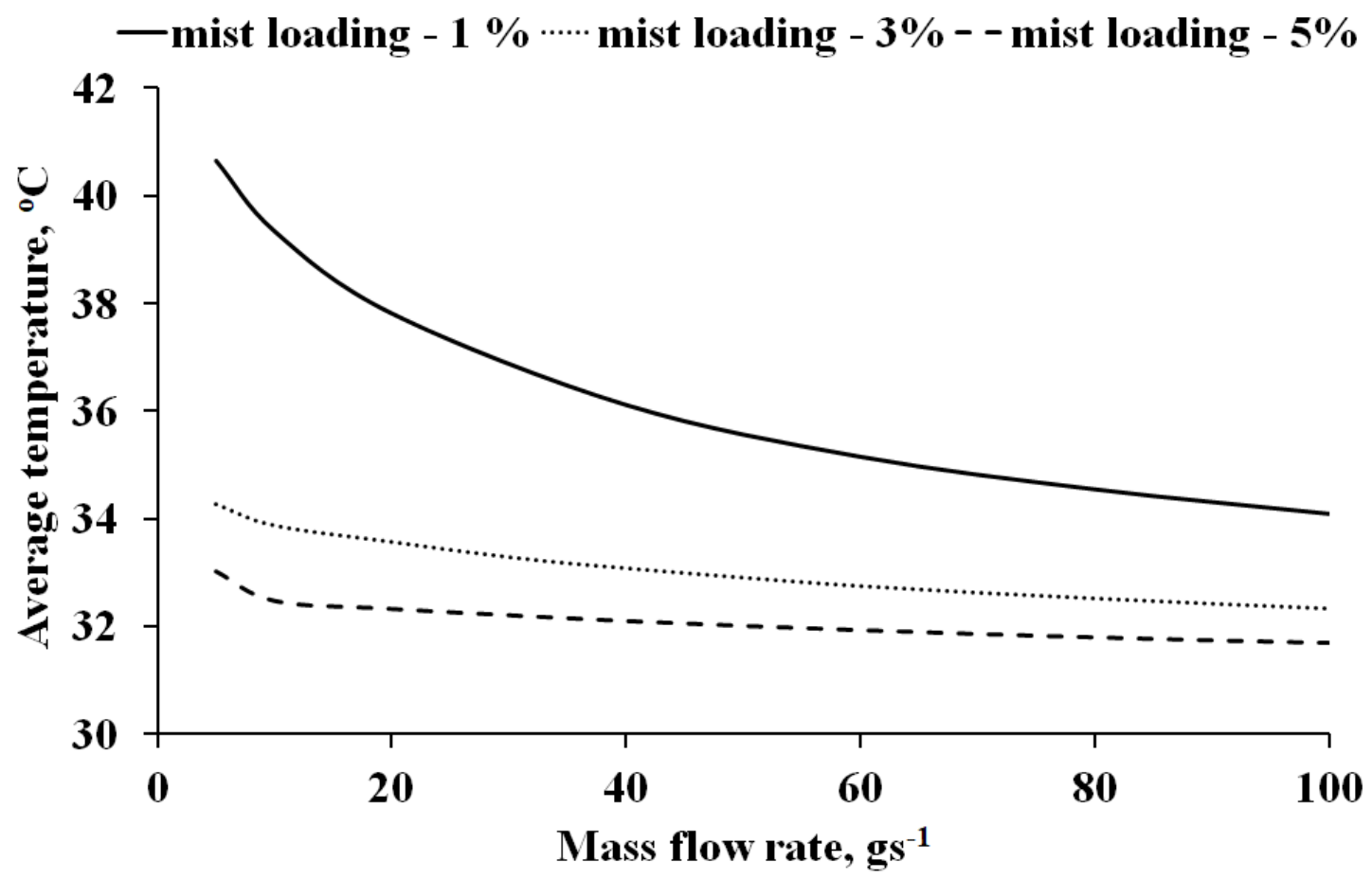


-mist loading - 1\% …mist loading - $3 \%$ - - mist loading - 5\%

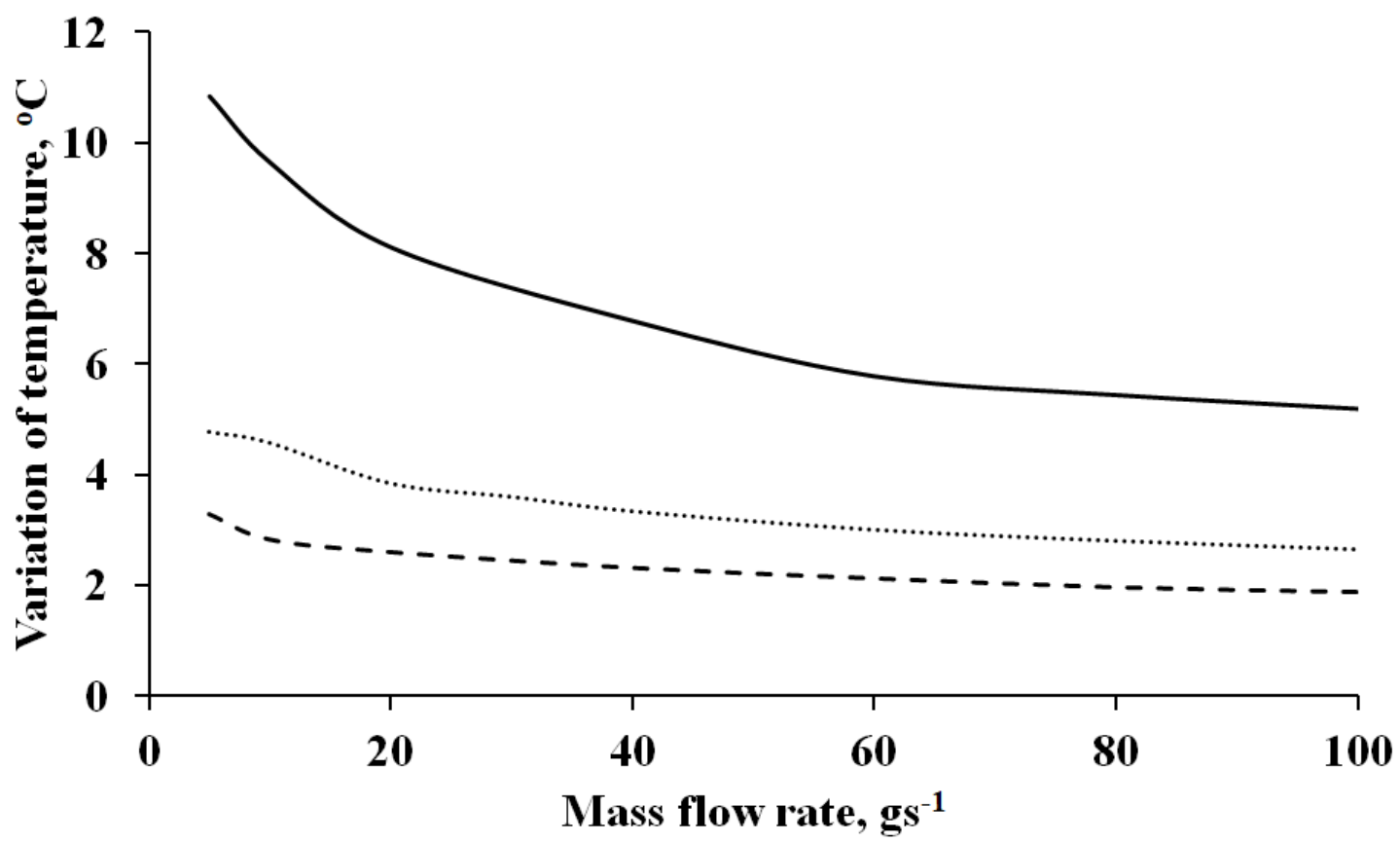


Temperature

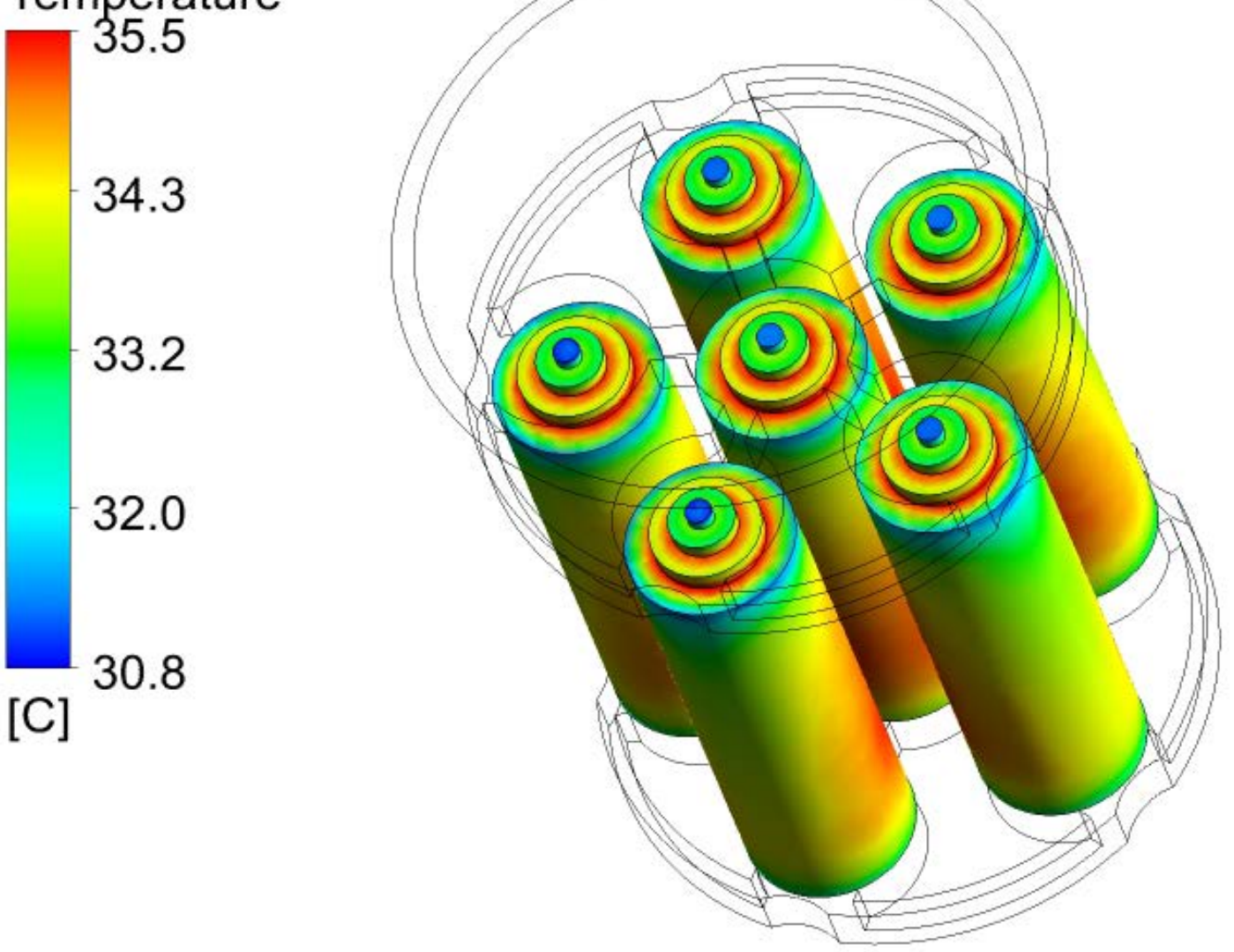




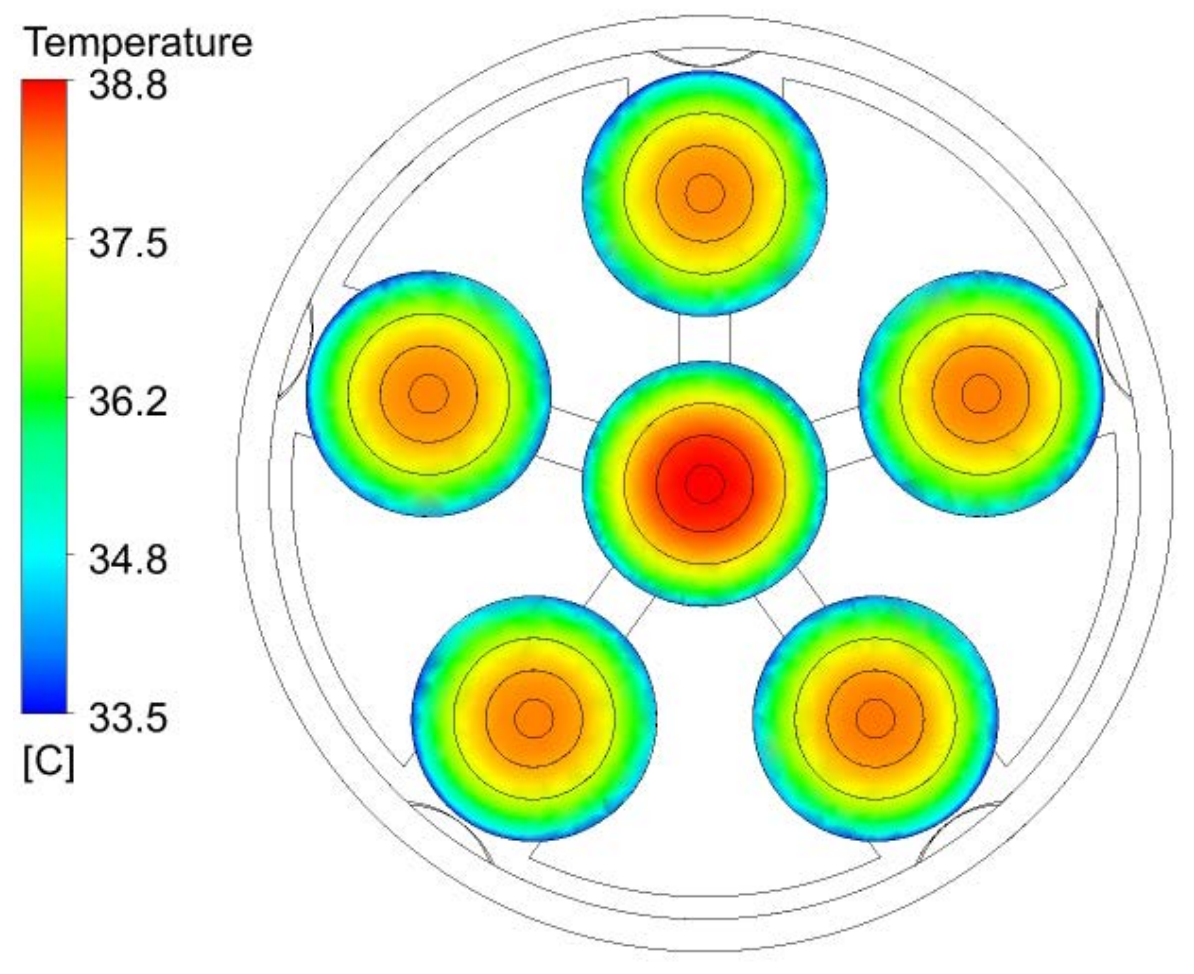


--- mist loading - 1\% …. mist loading - 3\% - mist loading - 5\%

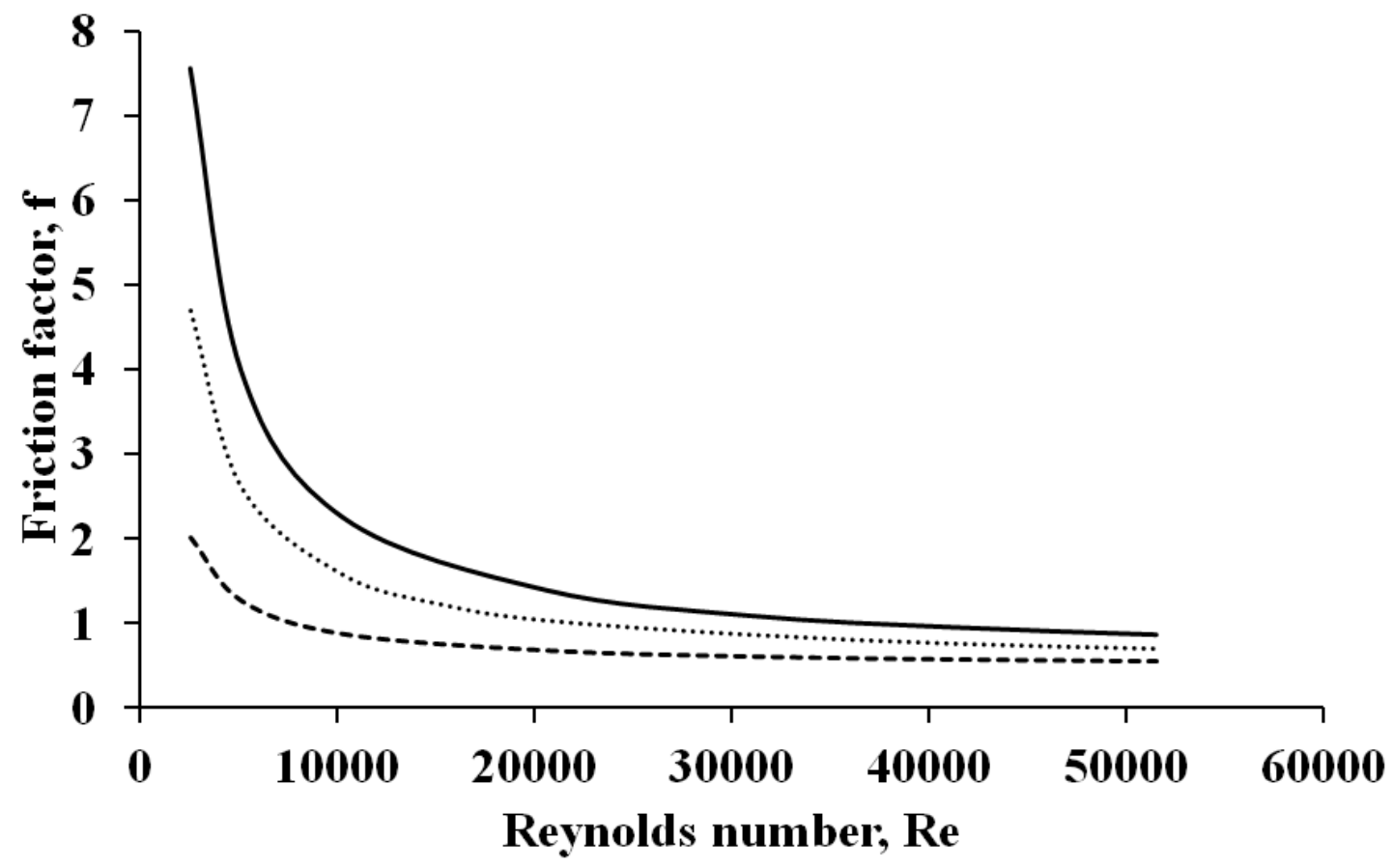




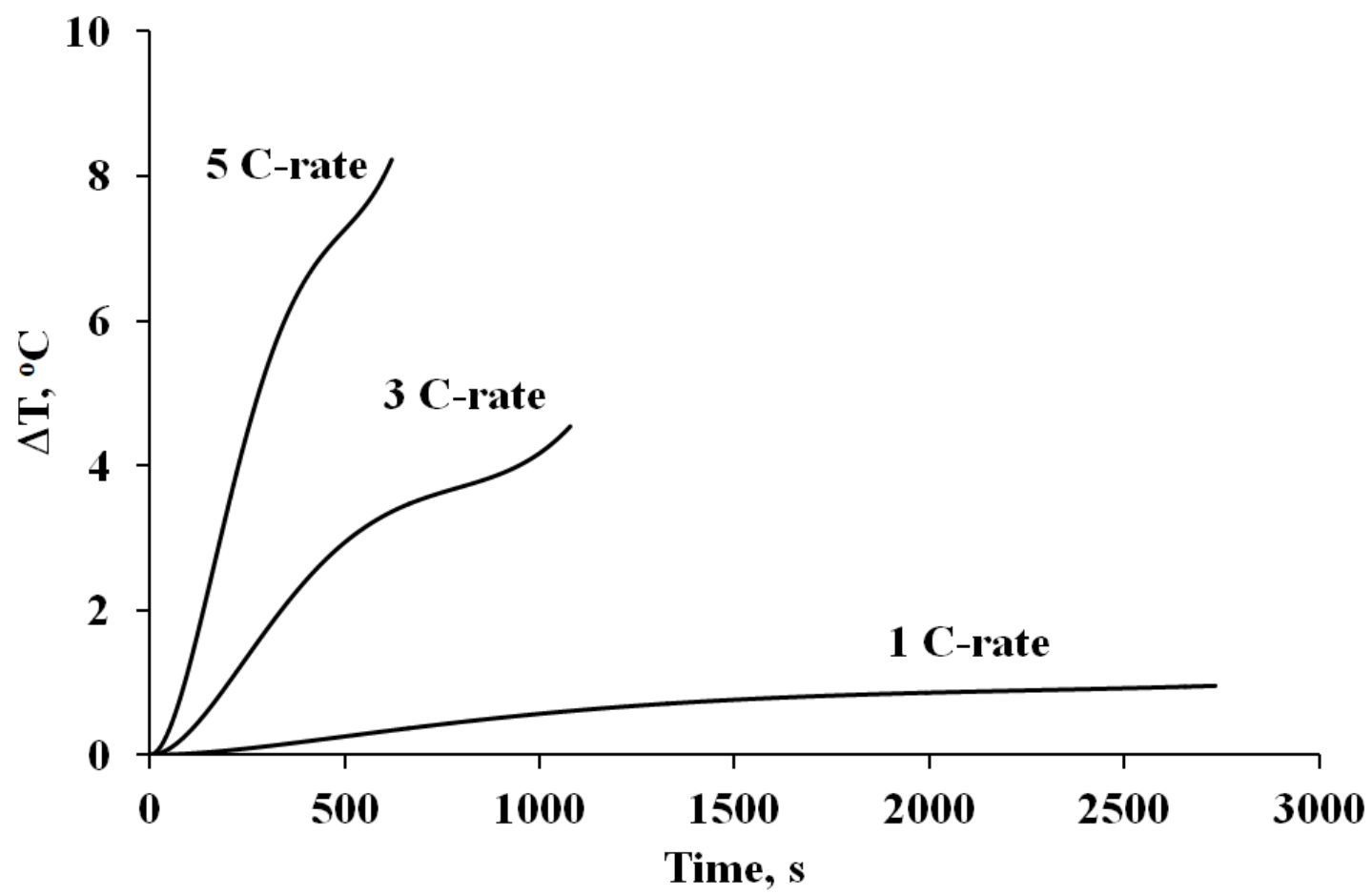




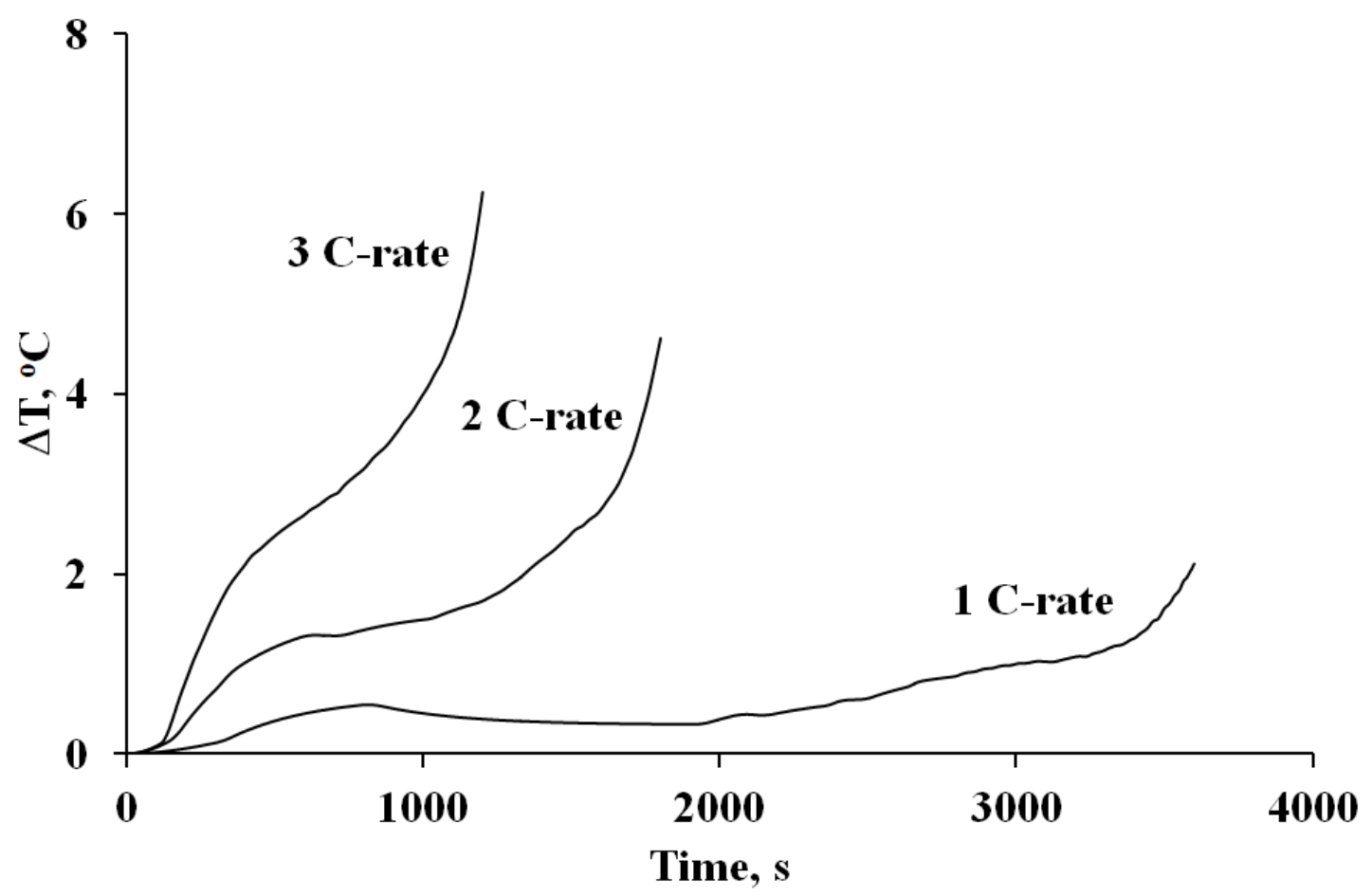




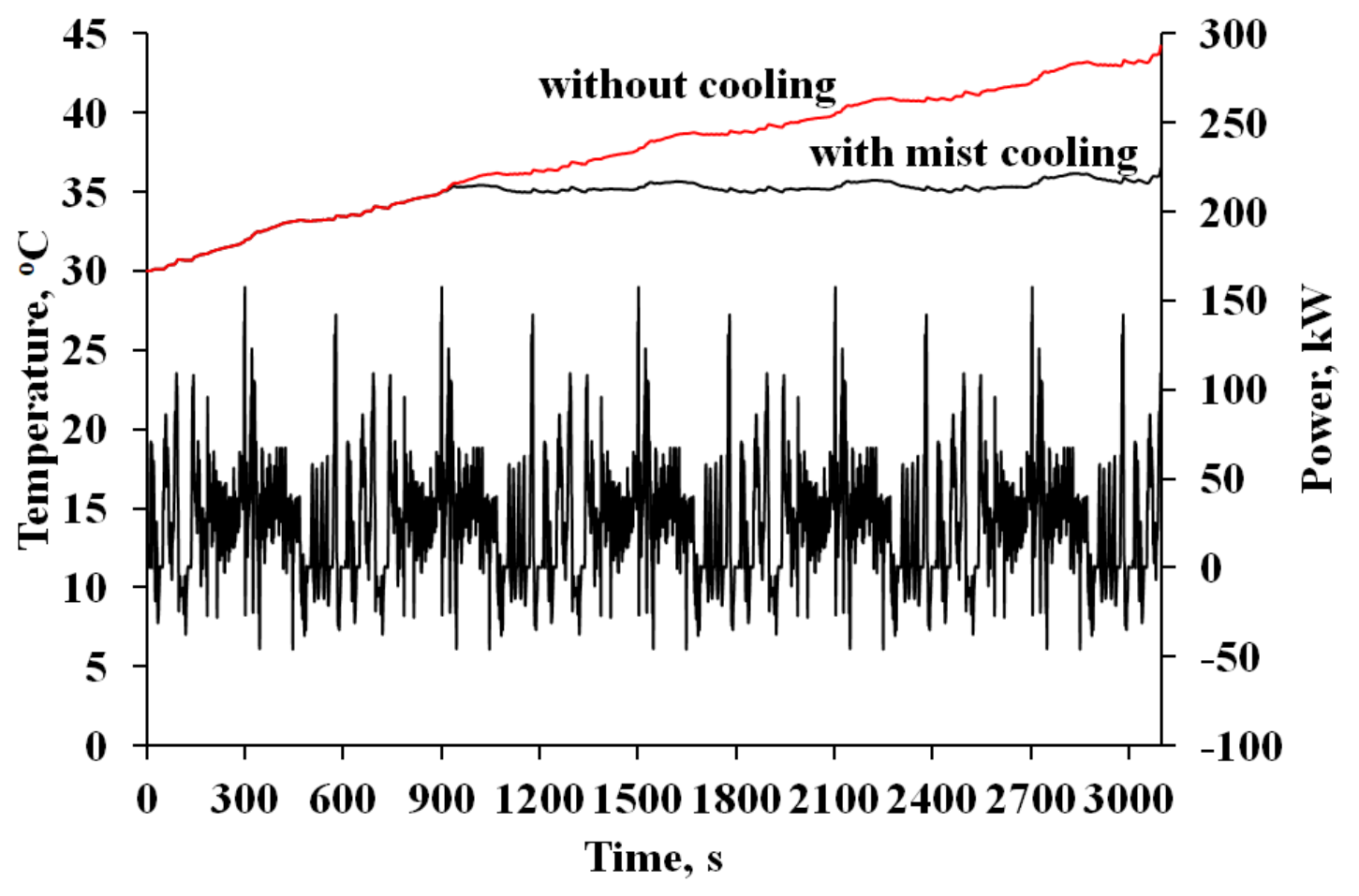

